\title{
PASARRIENDAS DE BRONCE EN LA PROTOHISTORIA PENINSULAR: A PROPOSITO DEL HALLAZGO DEL SOTO DEL HINOJAR-LAS ESPERILLAS (ARANJUEZ, MADRID)
}

\author{
JAVIER JIMÉNEZ ÁVILA \\ Junta de Extremadura \\ KENIA MUNOZZ LÓPEZ-ASTILLEROS \\ Universidad Complutense de Madrid
}

\section{Resumen}

La aparición de un pasarriendas de bronce en prospecciones superficiales realizadas en el yacimiento del Soto del Hinojar-Las Esperillas (Aranjuez, Madrid) y la revisión de una serfe de objetos de bronce (publicados unos, inéditos otros) que pueden leerse desde el punto de vista funcional en la misma dirección, jus. tifican un análisis de conjunto de los pasartiendas peninsulares orientalizantes e ibéricos, lo que permite una nueva aproximación al estudio del carto ligero en la Península durante la Primera Edad del Hierro.

\section{Summary}

A new bronze charriot terret found in the archaeological site of Soto del Hinojar-Las Esperillas (Aranjuez, Madrid) of a wellknown Iberian type and the study of new bronze rings and cases (a few of them unpublished) now intended as charriot terrets, lead to a global analysis of the Orientalizing and Iberian bronze terrets, allowing a new approach to the study of the chaniot during the First Iron Age (7th-5th cent. BC) in Spain and Portugal.

\section{EL YACMMIENTO DEL SOTO DEL HINOJAR-LAS ESPERILLAS (ARANJUEZ, MADRID)}

El yacimiento del Soto del Hinojar-Las Esperillas se emplaza en la margen izquierda de la confluencia del Tajuña y del Jarama no lejos de la unión de este último con el Tajo 
cerca de Aranjuez, a cuyo término municipal pertenece. Localizado durante los trabajos de prospección de la Carta Arqueológica de la Comunidad de Madrid ${ }^{1}$ y recogido en la Tesis Doctoral de uno de nosotros ${ }^{2}$, se recuperaron entonces abundantes materiales que indican una prolongada ocupación desde el Neolítico a la actualidad que quizá se deba a su privilegiada posición en el entramado de vías naturales de la cuenca media del Tajo (fig. 1).

Los materiales correspondientes a la Primera Edad del Hierro o Hierro Antiguo fueron localizados en grandes manchas superficiales de tierra cenicienta y forma circular $u$ ovalada tanto del sector situado en la terraza media, cerca de la casa del Soto del Hinojar, como del ubicado en la terraza baja que se extiende a sus pies, en el lugar conocido como Las Esperillas. Unas manchas que por sus dimensiones notables -en algunos casos de algo más de una decena de metros de longitud- podrian corresponder a estructuras de habitación más que a contextos funerarios.

La mayoría de dichos materiales son fragmentos cerámicos a mano de cocción predominantemente reductora. Corresponden, por un lado, a grandes vasijas para aimacenaje y cocina de paredes gruesas y superficies toscas o escobilladas con cuello indicado $y$ borde vuelto con digitaciones o pequeños trazos incisos (fig. 2: 13-15; fig. 4: 1-4) Son asimismo abundantes los vasitos y cazuelitas de paredes finas y perfiles carenados de diversos tipos, cuyas superficies, a veces bruñidas y otras veces pintadas en rojo, presentan en ocasiones sobre la carena mamelones de perforación horizontal y franjas incisas con retículas, dameros, rombos, bandas y triángulos contrapuestos relienos de líneas paralelas (fig. 2: 1-7 y 9-12; fig. 3: 1-11 y 13-18; fig. 4: 7-10 y 13-15) También se han recuperado numerosos cuencos hemiesféricos y troncocónicos eventualmente pintados en rojo y con apéndices perforados (fig. 3: 12) Más escasos son los recipientes con improntas de algún tipo de banda decorativa de material no cerámico (imetal, orgánico?) hoy perdido (fig. 4: 5 y 6). Finalmente, se documentaron algunos dientes de hoz en silex (fig. 2: 8) y un pasarriendas anular, posiblemente de bronce de sección circular segmentado transversalmente por una barra con desgastes en su parte central, que conservaba parte de un vástago vertical (fig. 6: 1). Salvo el pasarriendas, que constituye un hallazgo excepcional en la región, el repertorio material, fundamentalmente cerámico y lítico, recuperado en el Soto del Hinojar-Las Esperillas es similar al de otros yacimientos de la Primera Edad del Hierro de la cuenca media del Tajo como Cerro de San Antonio ${ }^{4}$. Camino de los Pucheros $\mathbf{1}^{5}$, Camino de las Cárcavas ${ }^{6}$, La Capellana ${ }^{7}$ y Puente Largo de Jarama ${ }^{8}$. cuyas fechas oscilan entre el siglo viI y finales del vil a. C. ${ }^{9}$. Dicha cronología se ve corro-

${ }^{1}$ Realizados en 1985 bajo la dirección de F Velasco, P Mena, j. Baena y B. Martínez.

${ }^{2}$ Muñoz, K. (1998: 1999a).

${ }^{3}$ Munoz. K. (e. p.).

4 Blasco, M.C., Lucas, M.R. y Alonso, M. A. (1991)

${ }^{5}$ Mữoz, K. (1993).

${ }^{5}$ López. I. y otros (1999)

${ }^{7}$ Blasco, M.C. y Baena, j. (1989)

${ }^{8}$ Muñoz. K. y Ortega, J. (1997).

${ }^{9}$ Blasco, M.C. y otros (1988), Muñoz, K. (1999b). 


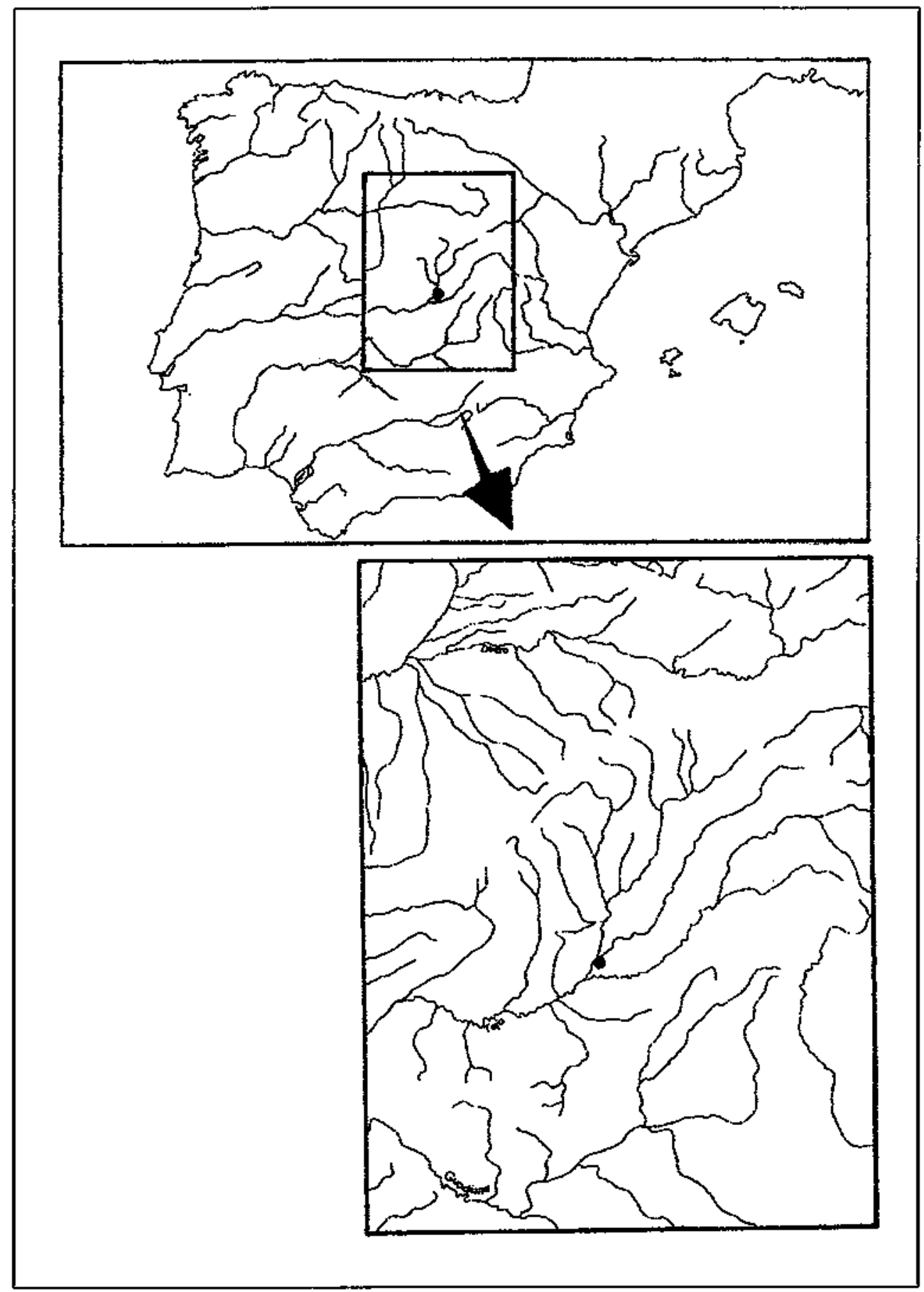

Figura 1.-Mapa de situación del yacimtento del Soto del Hinojar-Las Esperillas (Aranjuez, Madrid) 
borada por los paralelos concretos de algunos barros del Soto. Así, los perfiles de las cazuelitas bitroncocónicas (fig. 2: 1, 3, 4, 6 y 10-12; fig. 4. 10) y los motivos de triángulos rellenos de líneas paralelas que las decoran (fig. $2: 3$ y 6 ; fig. $4: 10$ y 14) se asemejan a piezas de Campos de Umas de los siglos ViI y vII a. $C^{10}{ }^{10}$, mientras que las bandas relienas de paralelas, los sectores punteados (fig. 4: 14) y la disposición de los triángulos en torno a franjas en zigzag, reservadas o rellenas de líneas paralelas verticales o puntos (fig. 2: 3) tienen raíz cogotiana y pueden considerarse, por tanto, antiguos ${ }^{11}$. Remiten al ámbito andaluz, en cambio, los grandes cuencos de carena alta y voluminoso cuerpo inferior hemiesférico: los que tienen carena marcada al exterior e interior (fig. 3: 3, 4, 6, 7 y 17) son bien conocidos en Cabezo de San Pedro, San Bartolomé de Almonte, El Carambolo y otros poblados del Bajo Guadalquivir en los siglos IX y VIil a. C. ${ }^{12}$; aquellos otros con carena alta indicada únicamente al exterior (fig. 3: 1, 2, 5 y 13-15) son frecuentes en yacimientos andaluces fechados entre 750 y 650 a. $\mathrm{C}^{13}$.

Dentro del contexto general del yacimiento del Soto del Hinojar-Las Esperillas conviene señalar que el pasarriendas, cuya tipología y cronología se discutirán más adelante, fue recuperado en una de las manchas ovales de la terraza media (Soto del Hinojar), acompañado exclusivamente por materiales de la Primera Edad del Hierro como los de la figura 4. La relevancia de la pieza llevó a que uno de nosotros (K. M.) planteara la excavación de la citada mancha con objeto de precisar cronológica y contextualmente el hallazgo. El sondeo, llevado a cabo en la primavera de $1993^{14}$, resultó, sin embargo, infructuoso. En efecto, no pudo localizarse estructura alguna a la que pudiera asociarse el mismo y que correspondiera a la gran mancha de ceniza superficial. Los materiales recuperados fueron fragmentos cerámicos diminutos y muy rodados (fig. 5) que, además de concordar con la cronología inicialmente propuesta por su similitud con los ya mencionados, reforzaban la hipotesis de que la estructura originaria, fuera cual fuese, habia sido arrasada por el intenso laboreo agrícola moderno.

Por último, no querríamos dejar de mencionar que en una mancha cenicienta muy próxima a la que proporcionó el pasarriendas se recuperó un elemento de hierro en forma de $T$ con remaches (fig. $6: 2$ ) que inicialmente se supuso correspondia a un refuerzo de rueda de carro. Le acompañaban en superficie cerámicas a mano de la Primera Edad del Hierro y algunos fragmentos indeterminados de cerámica a torno oxidante con decoración pintada de la Segunda Edad del Hierro. A pesar de su inicial adscripción fun-

${ }^{10}$ Ruiz Zapatero, G. (1985) 91, 406-410, 428, 550-551 y figs. 128,175 y 219: Maluquer de Motes, J. y otros (1990)

1 Almagro Gorbea, M. y Fernández-Galiano. D. (1980): fig. 14: Martinez, M. I. y Méndez. A. (1983) figs. 5 y 15; Delibes, G. y otros (1990): figs. 11 y 14: Blasco, M. C., Caile, J. y Sánchez-Capilla, M. I. (1991) figs. 36,43 y 45.

12 Ruiz Mata, D. (1995): figs. 3,4 y 15.

13 Pellicer. M. (1988-1989): 463 y fig. 5: 10, 12 y 13: Molina, F. (1978): tabla; Ruiz Mata, D. (1995) figs. 17 y 20 .

14 Con autorización de la Dirección General de Patrimonio de la Comunidad de Madrid y ninanciación de dicho organismo y de la Fundación-Instituto Universitario José Ortega y Gasset. 


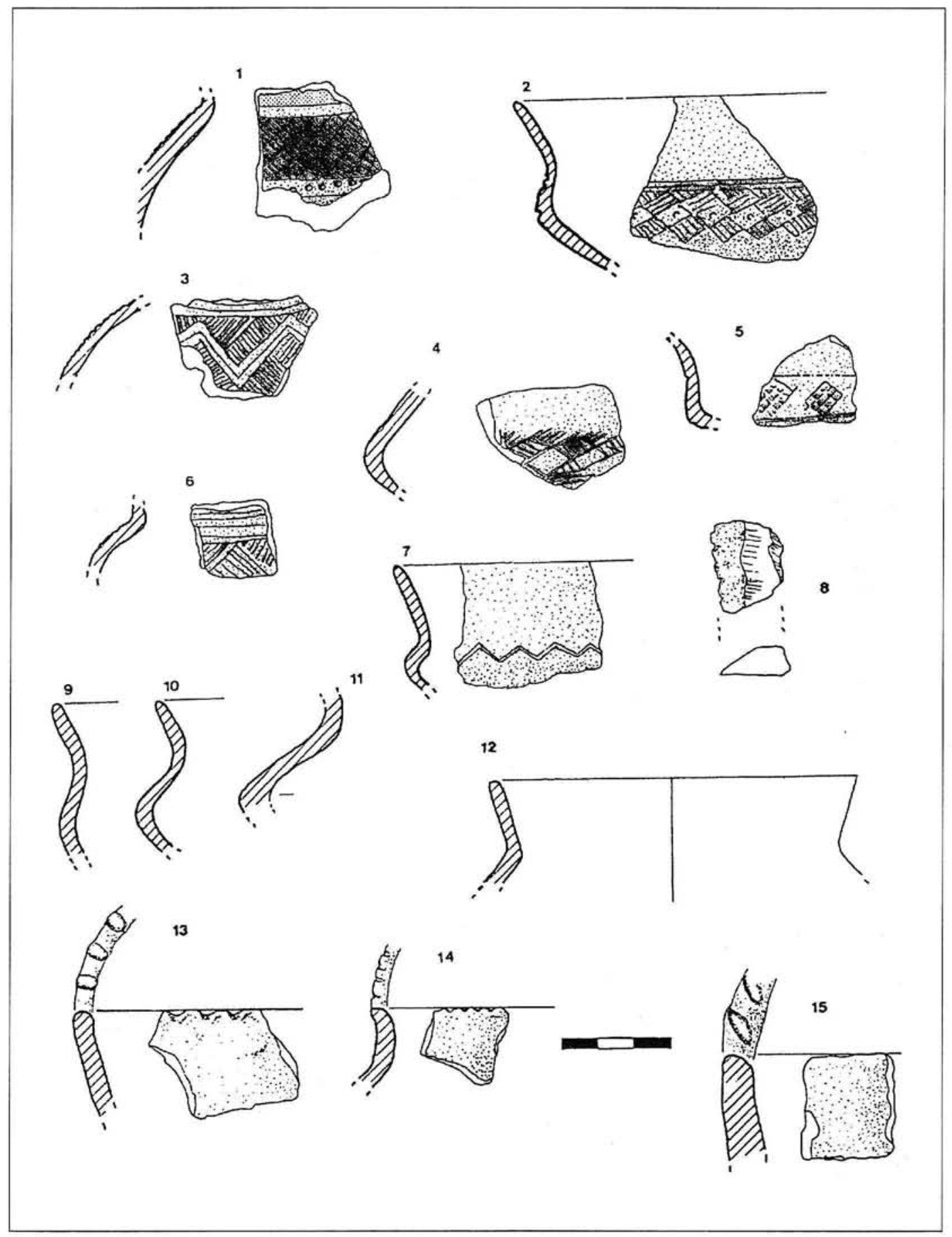

Figura 2.--Soto del Hinojar-Las Esperillas (terraza baja). Materiales recuperados en superficie 


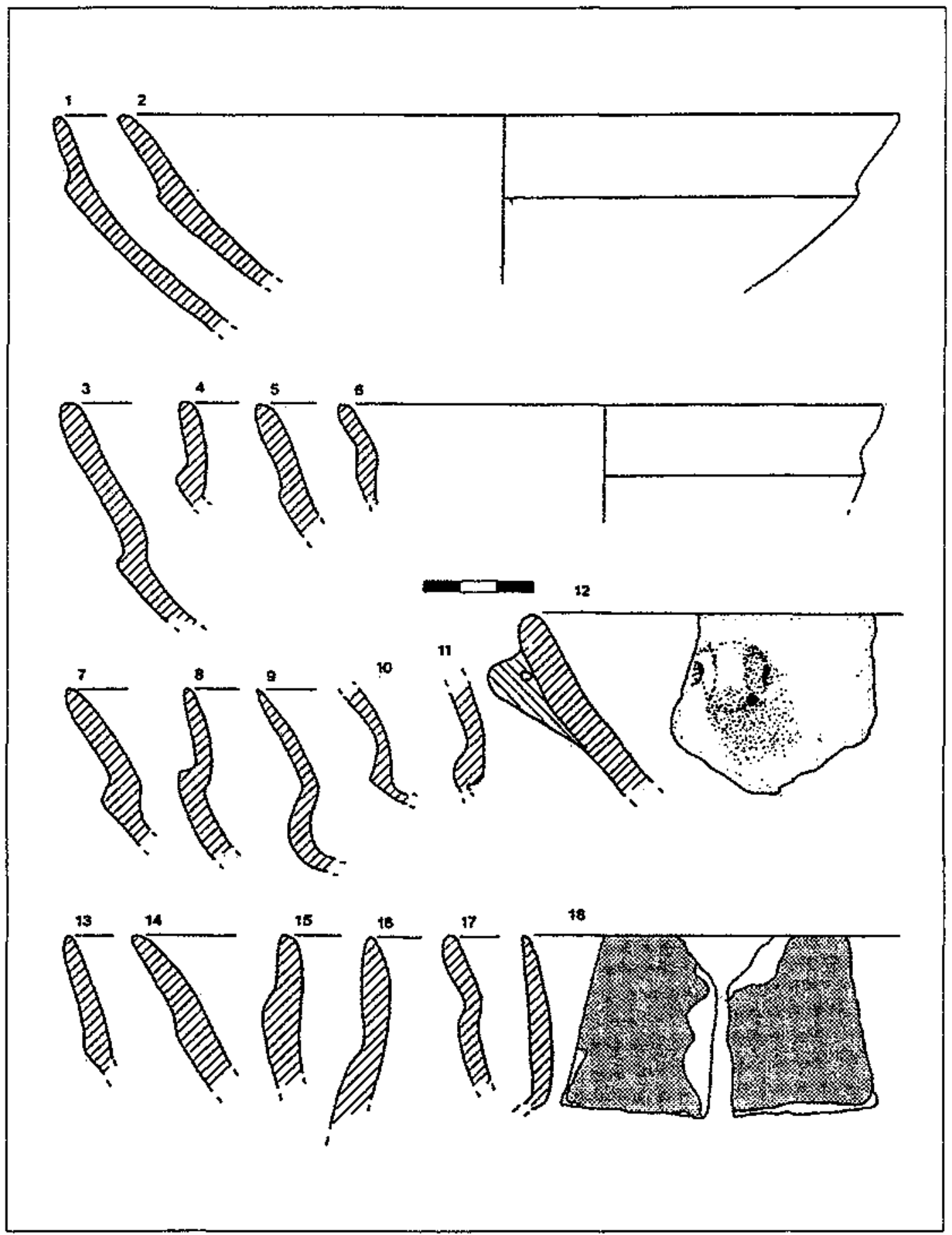

Figura 3.-Soto del Hinojar-Las Esperillas (terraza baja) Materiales recuperados en superficie 


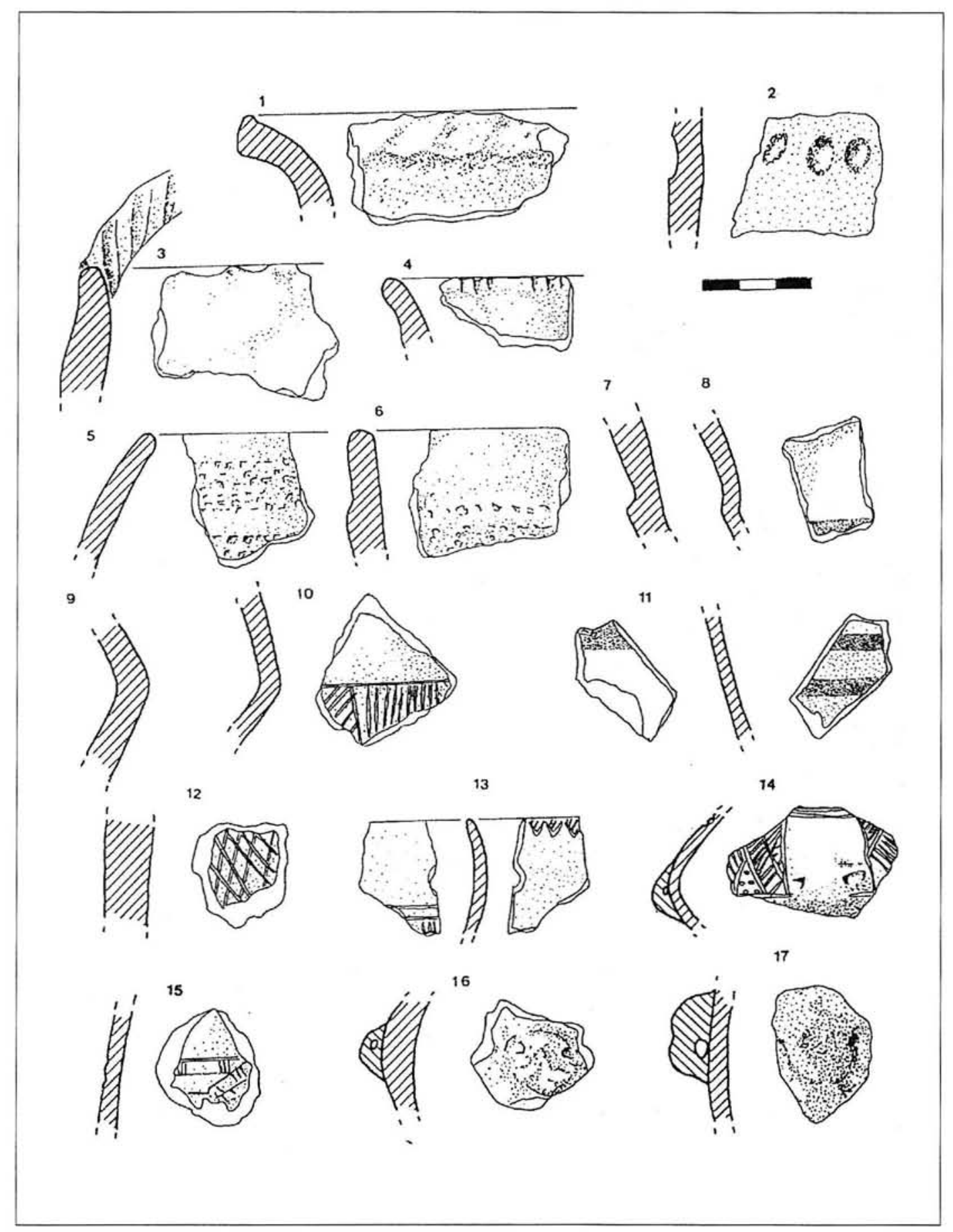

Figura 4.-Soto del Hinojar-Las Esperillas (terraza media). Materiales recuperados en superficie 


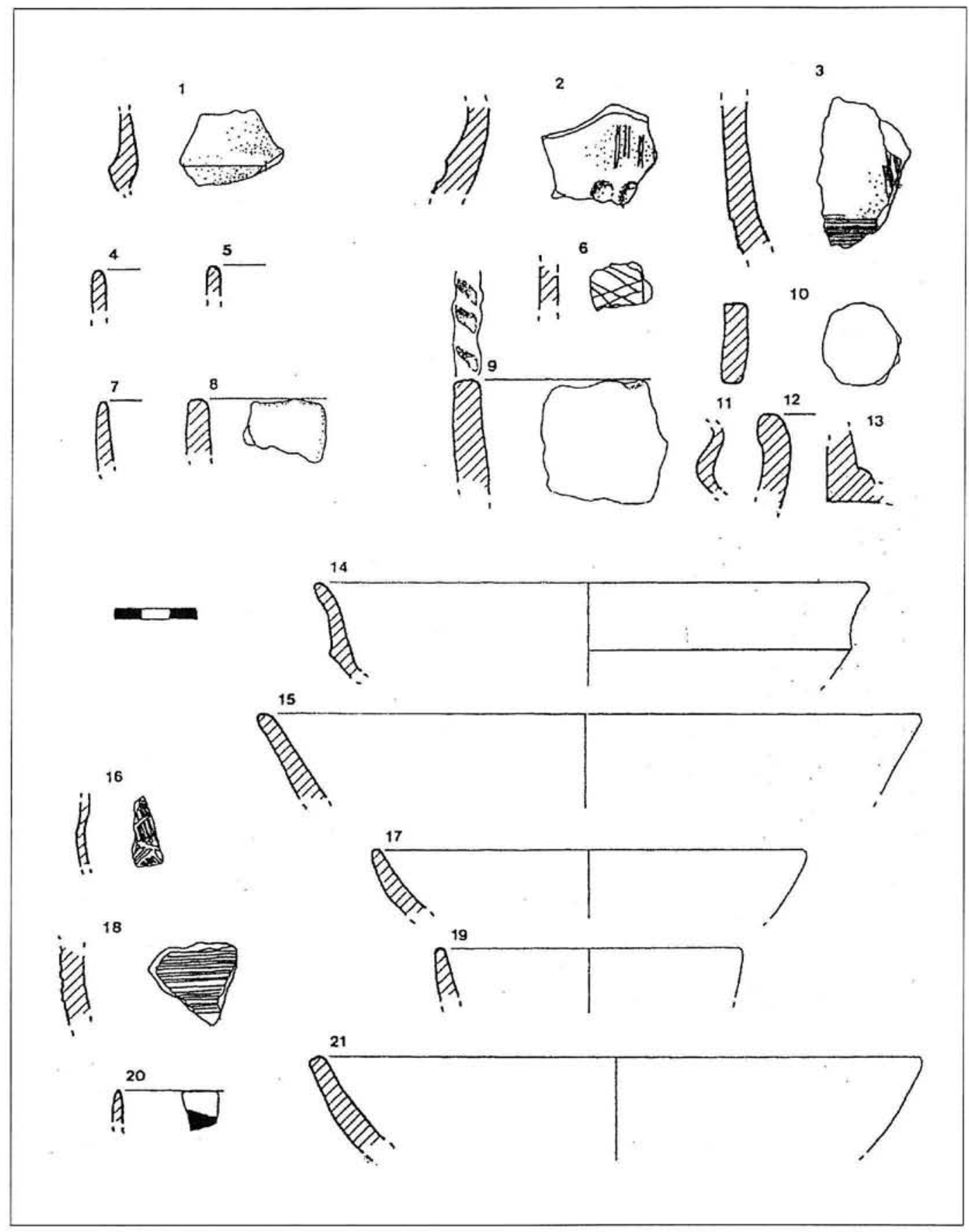

Figura 5.-Soto del Hinojar-Las Esperillas (terraza media). Materiales recuperados en la excavación de la mancha de ceniza donde apareció el pasarriendas 


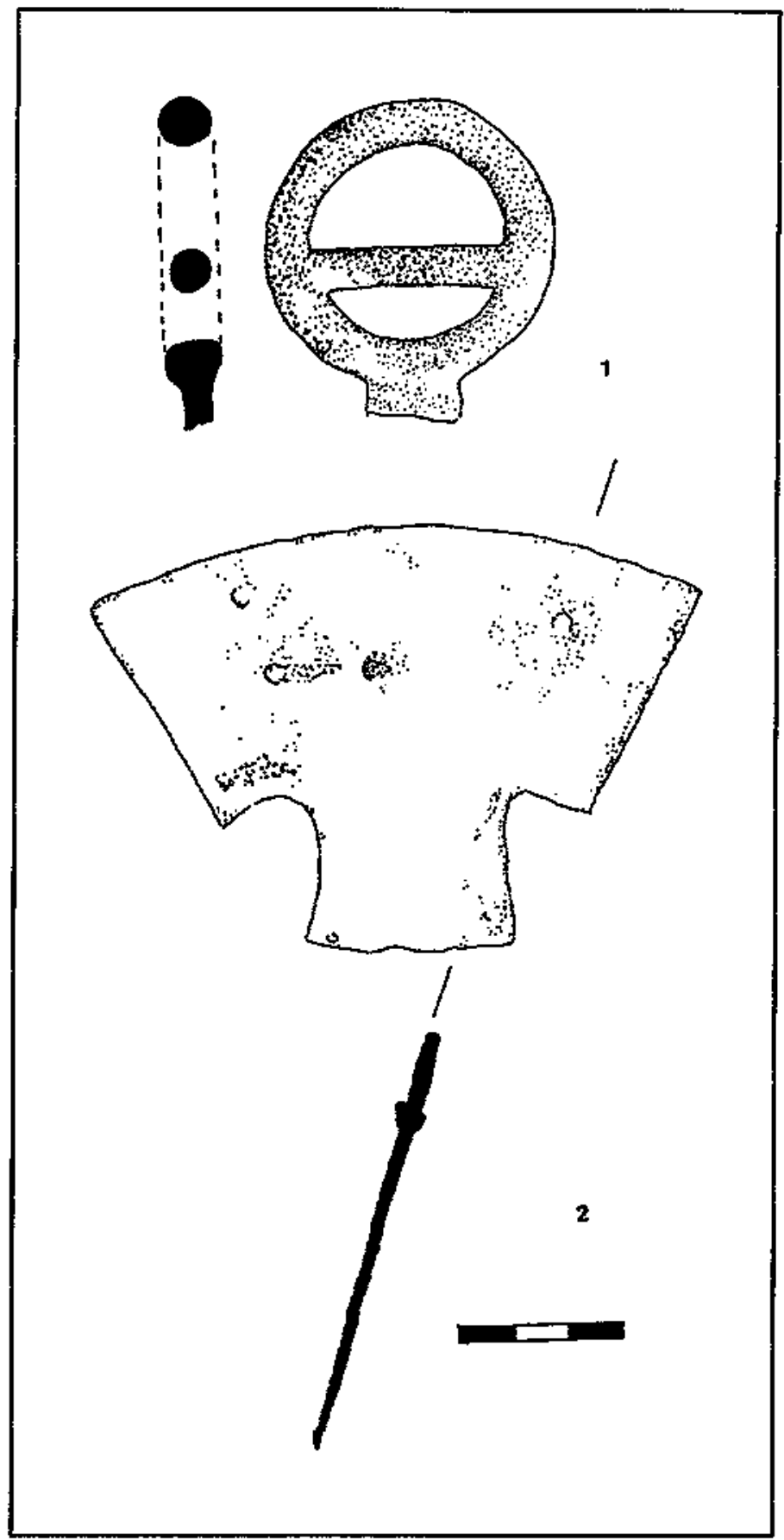

Figura 6.-Soto del Hinojar-Las Esperillas (terraza media) Pasarriendas de bronce y elemento de hierro recuperados en superficie 
cional y de la evidente similitud formal de este elemento con los refuerzos de ruedas de carros ibéricos hallados en yacimientos como Toya (jaén), Baza (Granada) o Mirador de Rolando (Granada) ${ }^{15}$ el diámetro que se obtiene al estudiar su curva externa $(30 \mathrm{~cm})$ es demasiado pequeño para identificarlo con uno de estos refuerzos de pina, faltando, además, en el tramo recto la característica sección curvada que permite su adaptación al contorno de los radios. No es aceptabie, por tanto, identificar esta pieza como un segundo elemento de carro, si bien es cierto que no nos ha sido posible proponer una funcionalidad ailternativa.

\section{PASARRIENDAS DE BRONCE EN LA PENÍNSULA IBERICA}

El pasarriendas es un elemento integrante de los arreos del tiro del carro ligero cuya función es, como fácilmente puede derivarse de su propia denominación, la de conducir las correas de las riendas desde los frenos instalados en la boca de los animales hasta las manos del conductor Su funcionalidad primaria es doble: por un lado evitar que las bridas se enreden y que pasen de un lado a otro en situaciones violentas durante el uso del vehículo y por otro, facilitar el manejo del tiro al provocar que la llegada de las riendas a las manos del auriga sobrevenga desde una posición inferior, actuando como verdadero punto de apoyo. La fórmula más sencilla y usual para configurar un pasarriendas es la de una simple anilla que puede ir unida a alguno de los elementos fijos del arnés mediante diversos procedimientos.

Dado que este tipo de artefactos requiere de una cierta resistencia, desde época temprana fueron fabricados en metal, algo que también se aprovechó para convertirlos en elementos ornamentales. Esto puede apreciarse ya en algunos pasarriendas metálicos hallados en las excavaciones de Sir L. Woolley en la Baja Mesopotamia, que aparecen decorados con figuraciones en bulto redondo y que coinciden por su forma con los ejemplares representados en los carros de guerra del denominado "estandarte de $\mathrm{Ur}^{n \mathfrak{} \mathfrak{6}}$ Estos pasarriendas, que se remontan al Tercer Milenio a. C., constituyen los ejemplares mós antiguos conocidos. Contrariamente a lo que podria pensarse, en los siglos posteriores la documentación de pasarriendas en las excavaciones del Próximo Oriente resulta mucho menos abundante.

Los pasarriendas metálicos son conocidos en la Peninsula Ibérica desde época relativamente antigua, al haberse hallado algunos ejemplares en excavaciones del siglo pasado, como las llevadas a cabo en la necrópolis portuguesa de Alcácer do Sal ${ }^{17}$, conservándose otros de procedencia desconocida en los fondos de museos nacionales y extranjeros desde épocas remotas. Sin embargo, no fue hasta los años setenta que, gra-

\footnotetext{
${ }^{15}$ Fernández-Miranda, M. y Olmos. R. (1986).

${ }^{16}$ Littauer, M. y Crouwel, J.H (1979) figs. 3 y 10.

${ }^{17}$ Schüle, W. (1969) : 280.
} 
cias a un trabajo de W. Culican sobre un ejemplar de la antigua Colección Vives, fueron reconocidos como elementos de arnés correspondientes a carros ${ }^{18}$. Desde entonces, su número ha ido creciendo hasta superar la docena y. prácticamente, se han convertido en la evidencia más clara de la presencia de vehículos ligeros en la protohistoria ibérica. De cara a la identificación funcional de estos objetos es especialmente clarificador su hallazgo en la tumba 17 de La Joya (Huelva) a ambos lados del forro metálico de la lanza de un carro cuyos restos también se hallaron in situ. junto al impresionante ajuar de esta sepultura ${ }^{19}$. Desgraciadamente, el resto de los ejemplares hasta ahora conocidos carece de buenos contextos, si bien en algún caso, como el conjunto recientemente publicado de Úbeda La Vieja (Jaén), aparecen asociados a bocados de caballo y botones de atalajes ecuestres que favorecen su lectura funcional en este sentido ${ }^{20}$.

Todos los pasarriendas hasta ahora publicados en la Península Ibérica responden, con más o menos variaciones, al modelo de armella segmentada unida a un robusto vástago vertical. A este grupo viene a sumarse el ejemplar madrileño del Soto del HinojarLas Esperillas que hace el número dieciséis de la serie. Sin embargo, creemos que existen una serie de objetos que hasta ahora no han sido reconocidos como pasarriendas y que debieron funcionar como tales, a juzgar por su disposición estructural, por las huellas de uso que presentan y por los contextos de los que, con mayores o menores dudas, proceden. Algunos de ellos son inéditos.

\section{Nuevos pasarriendas}

Aparte del nuevo ejemplar procedente del Soto del Hinojar-Las Esperillas, que corresponde al tipo clásico de anilla segmentada y vástago (en este caso perdido), existen una serie de objetos de bronce protohistóricos que deben ser tenidos por pasarriendas $\mathrm{y}$, consecuentemente, relacionarse con atalajes de carros.

El primero de estos nuevos pasarriendas se halló en la habitación $\mathrm{H}-8$ del edificio central de Cancho Roano (Zalamea de La Serena, Badajoz), y ha sido relacionado con una serie de cadenas vinculadas a su vez con arreos ecuestres, aunque la reconstrucción funcional aportada por su editor no es del todo clara ni resulta satisfactoria ${ }^{21}$. El objeto reproduce en lo básico el esquema de los pasarriendas de vástago con algunas modificaciones: se trata de una simple anilla sin segmentación central unida a un vástago trapezoidal ra-

\footnotetext{
${ }^{18}$ Culican. W. (1971).

${ }^{19}$ Ganido, J.P y Orta. E.M. (1978): 76-81, fig. 33, lám. LVII.

20 Ferrer, E. y Mancebo, J. (1991)

${ }^{21}$ Maluquer, J. (1983): fig. 21, 68-70. Tampoco son correctas las medidas ni la escala a la que, se dice. se ha reproducido en la Memoria. No pueden unirse a esta argolla los elementos de la figura 20 porque unos y otros son herméticos. Por otra parte, si, como propone Maluq̨uer. las dos ptezas en U de la figura 20 ciñen el cuello del caballo, la anilla en cuestión obligaría a que el animal tuviera el cuello pegado al elemento de sujeción al que se uniría el vástago.
} 
nurado, a la que se añade una lámina en disposición horizontal ligeramente curvada. Esta lámina o refuerzo presenta dos agujeros cuadrados situados delante y detrás de la anilla que, contrariamente a lo que puede pensarse a partir de los datos publicados, son independientes y no constituyen una única ranura alargada. A las analogias formales que unen esta pieza con los pasarriendas de vástago hay que sumar, de cara a su identificación funcional, otros elementos de juicio: así, la adopción del refuerzo que, por su forma curvada, se adaptaría especialmente bien al contorno cilíndrico del yugo lignario que es, como con posterioridad veremos, donde se insertarian este tipo de guias; la presencia de profundas huellas de uso en el interior del aro debidas al roce del cuero y también, aunque en menor medida, el contexto arqueológico en que fue hallada, pues la habitación $\mathrm{H}-8$ de Cancho Roano fue pródiga en objetos de bronce relacionables con atalajes ecuestres y elementos de tiro, entre ellos, varios bocados de caballo, cadenas, etc. De este mismo lugar procede, recordémoslo. uno de los pasarriendas de vástago y anilla segmentada ya reconocidos ${ }^{22}$. Es importante subrayar que todos los elementos de carro hallados en este yacimiento corresponden al tiro y no a la caja ni al tren, pues la interpretación como tapacubos propuesta inicialmente para un objeto naceliforme procedente del patio $12^{23}$, no resulta del todo viable $^{24}$, habiéndose señalado ya otras lecturas alternativas ${ }^{25}$.

La suposición de que esta pieza de H-8 correspondia al pasarriendas de un carro nos la confirmó el descubrimiento de una serie de objetos similares en una colección particular de la provincia de Sevilla que aprovechamos para dar a conocer aqui ${ }^{26}$.

Un primer grupo está constituido por tres grandes pasarriendas que forman parte de un gran conjunto de bronces y hierros que, con práctica seguridad, se integrarian en el tiro de un carro. Dadas las características de este trabajo, hemos seleccionado únicamente los pasarriendas, pero se puede adelantar que en el mismo conjunto aparecen elementos que destacan sobremanera por su parecido con los atalajes ecuestres documentados en Cancho Roano: hay abundantes cadenas, dos clavos decorados con espirales laterales iguales a los encontrados en las ruinas del "palacio-santuario", dos agarres en forma de D también iguales a los de Zalamea de La Serena ${ }^{27}$, y un gran número de piezas diversas afectadas por el fuego. Proceden de excavaciones ilicitas realizadas, al parecer, en las inmediaciones del poblado cordobés de Ategua, en lo que tal vez sea su necró-

${ }^{22}$ Malıuquer, J. (1981): lám. XL. Su procedencia, fuera del edificio principal en la zona sur no hace descartable que originariamente estuviese depositado en H-8.

${ }^{23}$ Maluquer, J. (1983): 70-72; fig. 23.

${ }^{24}$ Los tapacubos requieren de un desarrollado disco para que la rueda no se salga y de una chaveta transversal para su sujeción. Ni una ni otra están presentes en esta pieza a la que, además, le sobraría el vástago central.

${ }^{25}$ Almagro Gorbea, M. Dominguez, A. y Lopez-Ambite. F. (1990): 275, n. 21

${ }^{26}$ Se trata de la Colección Aihonoz, a la que pertenecen algunos pasarriendas ya dados a conocer (Ferrer, E. y Mancebo, J.. 1991). En la actualidad se están dando pasos para su traspaso al Estado. Agradecemos a D. Ricardo Marsal, su actual propietario, el habernos permitido acceder a estos objetos y el habernos facilitado hasta extremos verdaderamente encomiables su estudio.

${ }^{27}$ Maiuquer, J. (1983): figs. 18 y 19. 
polis, pues junto a estos objetos metálicos se hallaron una copa griega de tipo Cástulo con la parte interior de las asas en reserva y una urna de cerámica ibérica pintada con bandas horizontales de color rojo ${ }^{28}$. Este conjunto de bronces es, sin duda, uno de los más interesantes de cara al conocimiento del carro ligero en el horizonte ibérico antiguo y su estudio, del que la presentación de los pasarriendas constituye un simple avance. aportará importantes novedades en este campo.

Ciñéndonos ya al análisis de los pasarriendas de este haliazgo, hay que decir que responden a dos modalidades diferentes: la primera reproduce el esquema de la pieza de Cancho Roano anteriormente descrita: anilla simple unida a un vástago perforado -que en este caso adopta el aspecto de un eslabón- e interposición de una placa horizontal de forma rectangular ligeramente curvada. Se conservan dos ejemplares de este tipo que, contrariamente al ejemplar de Zalamea, se nos presentan profusamente decorados, ya que las placas horizontales acogen sendas palmetas trabajadas en los ángulos y además. cubren su superficie con una serie de impresiones foliformes que, en raros casos, llegan a calar la lámina (figs. 7 y 8). Desde el punto de vista puramente formal también existen algunos puntos de discordancia con el pasarriendas extremeño: aquéllos no presentan los calados cuadrados (tal vez relacionables con el sistema de ajuste) y el vástago inferior es de sección circular en vez de laminar. Como rasgos destacados de estos pasarriendas hay que señalar el profundo desgaste que el cuero ha producido en el interior de las anillas y la presencia de una argolla de hierro incrustada en la parte inferior de uno de ellos, rodeando el vástago inferior. La segunda modalidad de este grupo ategüense está representada por un único ejemplar. La anilla y el vástago se adecúan al modelo ya visto, pero en lugar de la lámina o refuerzo curvado presenta una complicada guarnición trabajada en placa de bronce que forma una especie de cajetín troncopiramidal cerrado por cuatro de sus lados. Al igual que los otros ejemplares de su grupo se decora con una palmeta en la parte superior y con calados foliformes en toda la superficie de la guarnictón (fig. 9). Entre la amalgama de bronces comidos por el fuego de este conjunto se reconocen los posibles restos de otro pasarriendas de este tipo, lo que completaría el juego de cuatro anillas propio de los carros de doble tiro.

A esta modalidad de pasarriendas con refuerzo complejo corresponden otros dos ejemplares conservados en la misma colección y procedentes, al parecer, del lugar conocido como Dehesa de Alcurrucén, en el término de Pedro Abad (Córdoba). Parece que fueron hallados juntos, asociados a dos finos pasadores de bronce de extremos aplanados y arrollados (fig. 10:3 y 4), sin que existan más datos sobre su contexto. En los recovecos del metal conservaban restos de ceniza. Se trata igualmente de anillas redondas unidas a otra especie de argolla oblonga más estrecha que hace las veces de vástago perforado. Están reforzados con una placa de bronce fundida conjuntamente con las argollas, que adopta una disposición alabeada y una forma trapezoidal si se la observa

${ }^{28}$ Estos objetos tamblén se encuentran en la Colección Alhonoz. Evidentemente, hay que mantener reservas sobre el carácter de conjunto cerado de este hallazgo. pero no deja de ser digno de tenerse en cuenta que un conjunto tan similar a los bronces de Cancho Roano se vincule con la misma ergologia cerámica que aparece en este yacimiento. 
desde arriba y de tendencia triangular si es vista desde los laterales. Estos ejemplares de Pedro Abad se presentan desprovistos de decoración (fig. 10).

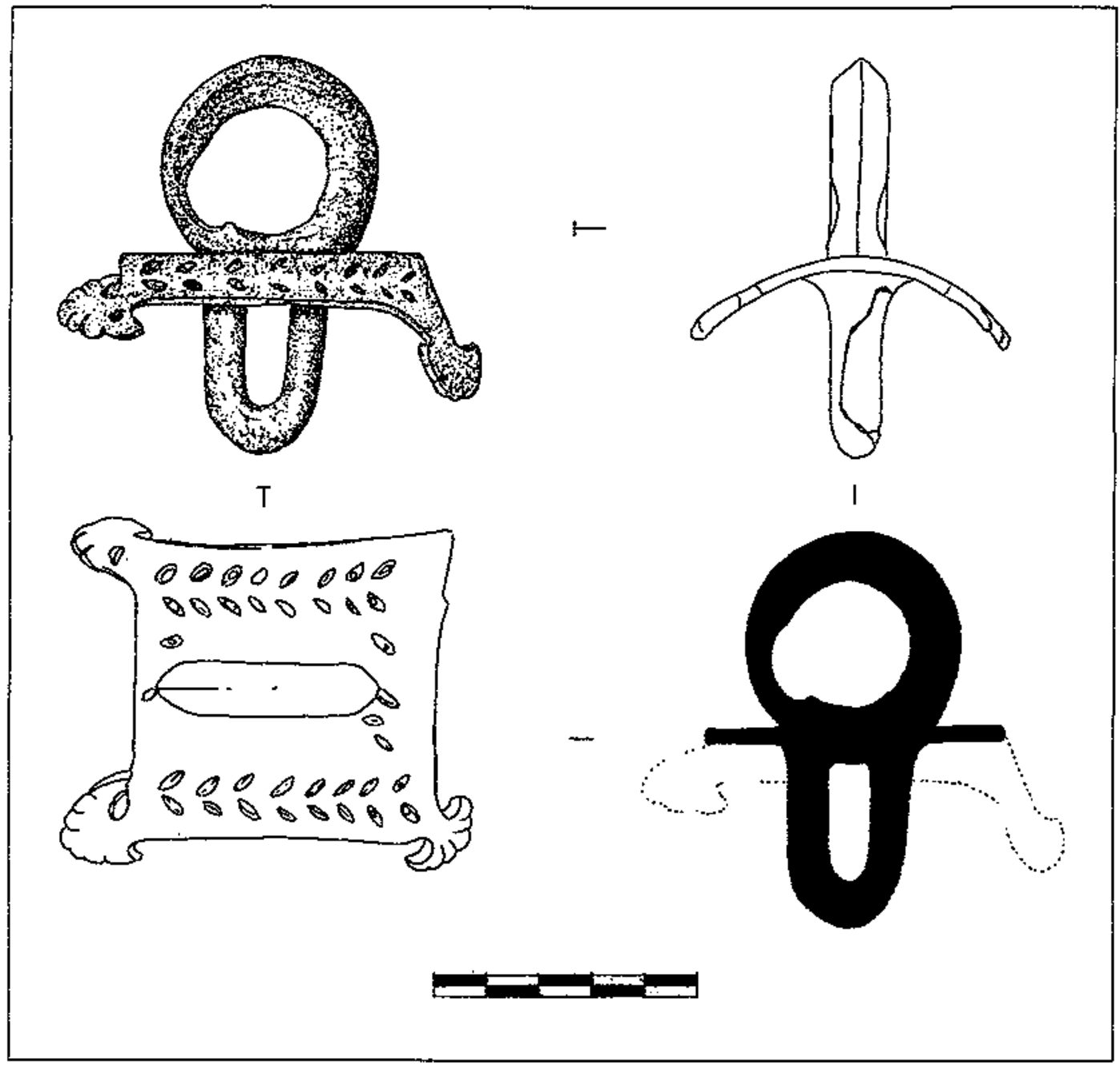

Figura 7.-Pasarriendas de bronce de Ategua (7). Colección Alhonoz. Cat. 18

Una vez unidos al grupo de los pasarriendas hispánicos estos ejemplares dotados de refuerzo laminar, parece conveniente considerar como pasarriendas (en sentido amplio) y añadir al grupo las fundas o revestimientos zoomorfos de Máquiz (Mengibar, Jaén) que han sido plausiblemente interpretados como elementos de yugo en recientes trabajos ${ }^{29}$. Abundando en esta interpretación, el vástago perforado que aparece en el inn.

${ }^{29}$ Jaeggi. O. (1992), cit. en Ruano, E. (1992). 
terior de los prótomos de lobo debería relacionarse funcionalmente con los vástagos ranurados de Cancho Roano, Ategua y Pedro Abad, y los pernos fragmentados que brotan del dorso de estas piezas bien pudieran ser arranques de otras tantas anillas para riendas. como ya propusiera M. Almagro Basch, que los leyó, no obstante, como forros de lanza o timón ${ }^{30}$. Esta visión como fortos de yugo, que parece muy convincente para las dos piezas con cabezas de lobo conservadas en el M. A. N., que formarian un conjunto coherente, podría aplicarse también a los dos objetos que se conservan en la Academia de la Historia, que presentan elementos relacionables con esta misma función como revestimientos, vástagos y anillas, pero que formarian parte de un equipo incompleto (fig. 14: C.2).

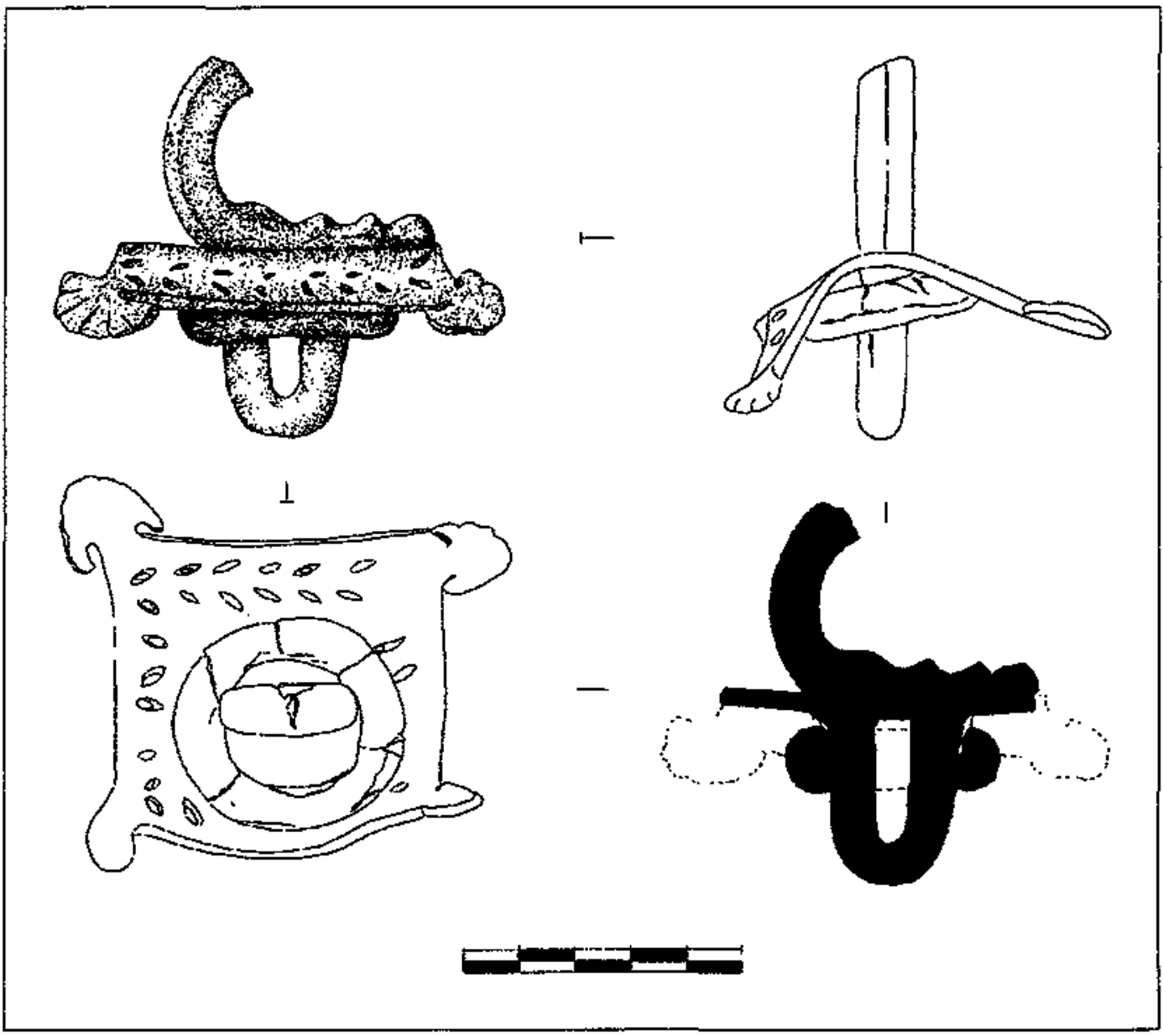

Figura 8.--Pasarriendas de bronce de Ategua (?. Colección Alhonoz. Cat. 19

39 Almagro Basch, M. (1979): 176 ss. 


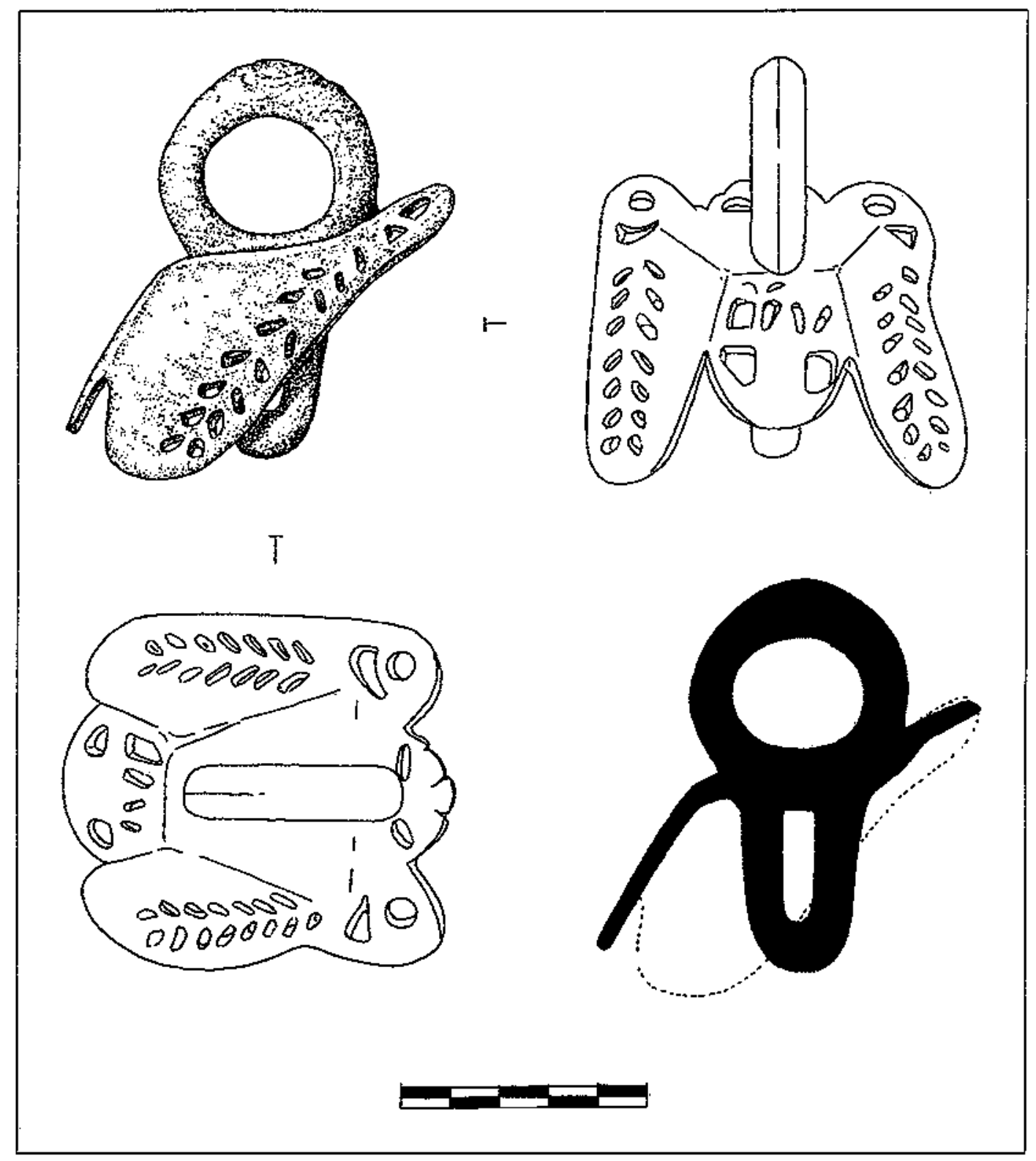

Figura 9.-Pasarriendasdie bronce de Ategua (7). Colección Alhonoz. Cat. 20 


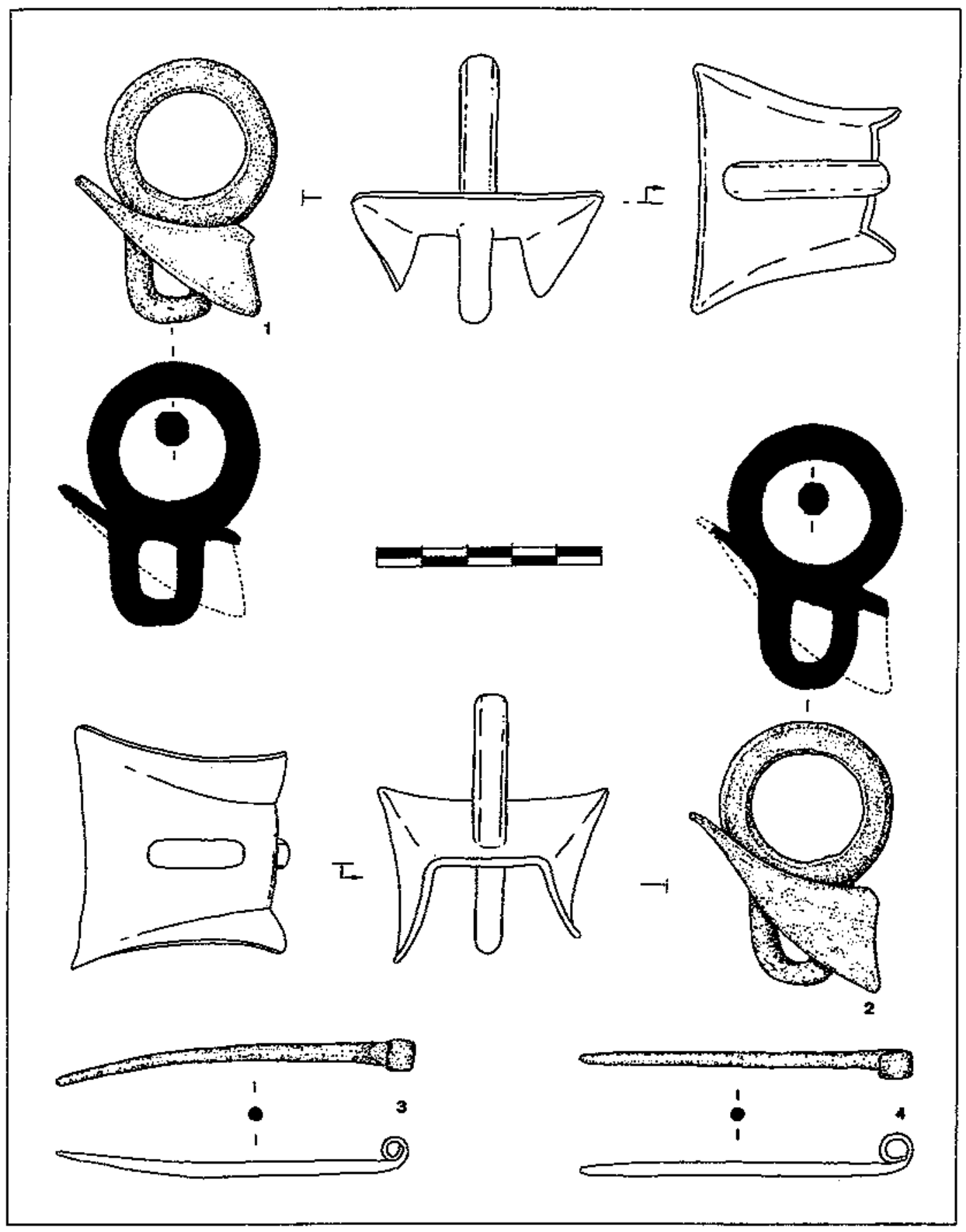

Figura 10.-Pasarriendas y vástagos de bronce de Peơro Abad (0). Colección Alhonoz. Cat 21 y 22 


\section{Tipología}

Con todo este conjunto de objetos identificables como pasariendas hoy estamos en disposición de elaborar una primera tipologia de los mismos, de cara a una posterior valoración cultural. A priori podemos establecer dos grupos de pasarriendas de bronce: un primer grupo lo formarian los ejemplares que hasta ahora han sido reconocidos como tales por la investigación, es decir, los configurados por una anilla segmentada y un simple vástago vertical. Podemos denominarlos pasarriendas de vástago y anilla segmentada o, simplemente, pasarriendas de vástago. Con la incorporación del nuevo ejemplar del Soto del Hinojar-Las Esperillas son ya dieciséis las unidades que cabe incorporar a este grupo 1. Al esquema fundamental de anilla y vástago se presentan una serie de tipos y variantes (fig. 11).

Tipo I (Huelva): Pasarriendas discoidales: conformados como una placa redonda con un hueco circular en el centro y una ranura rectangular por debajo que deben reproducir funcionalmente los dos sectores que resultan de segmentar el anillo en el tipo II. A este modelo responden los cuatro pasarriendas prácticamente idénticos hallados en la tumba 17 de la necrópolis de La Joya (Huelva) y sólo ellos (cat. 1-4).

Tipo II (Alboloduy): Pasarriendas anulares: la parte superior se constituye en una verdadera anilla segmentada por una barra diametral de sección variada. Se pueden agrupar en dos subtipos:

Il.1: Simples: responden a la descripción dada y se incluyen en él seis ejemplares procedentes de El Peñón de la Reina (Aiboloduy, Almeria) (cat. 5): Cancho Roano (Zalamea de La Serena, Badajoz) (cat. 6); Cástulo (Linares, Jaén), de donde proceden tres unidades (cat. 7-9) y el ejemplar de Soto del Hinojar-Las Esperillas (Aranjuez, Madrid) aquí presentado (cat. 10).

II.2: De crestería: incorpora al tipo básico una decoración tridimensional sobre la parte superior de la anilla a modo de crestería cuya temática es una sucesión de elementos vegetales. Cabe subdividir este grupo en dos variantes: II.2.a) en que la crestería se compone de puntiagudos capullos cerrados y que contiene un ejemplar de Alcácer do Sal (Portugal) (cat. 11), otro de procedencia desconocida conservado en el Museo de Barcelona (cat. 12) y tres ejemplares asociados a otros elementos de arnés procedentes de Úbeda la Vieja recientemente publicados (cat. 13-15). II.2.b) Integrado por un único ejemplar de procedencia desconocida y conservado en la Hispanic Society of America donde la cresteria se complica en una alternancia de capullos cerrados y palmetas fenicias de gran efecto plistico (cat. 16).

El conjunto podría subdividirse aún más atendiendo a criterios variados como la sección del vástago (cuadrada o rectangular) o a aspectos técnicos concernientes a la calidad del acabado, pues algunos pasariendas de cresteria presentan los capullos trabajados en perfecto calado (las piezas del Museo de Barcelona y Alcácer do Sal) mientras que en otros (los de Úbeda la Vieja) el espacio entre los elementos que componen la decoración está empastado por el metal vertido durante la fundición. Incluir estos criterios no haria, empero, sino complicar la clasificación inútilmente. 


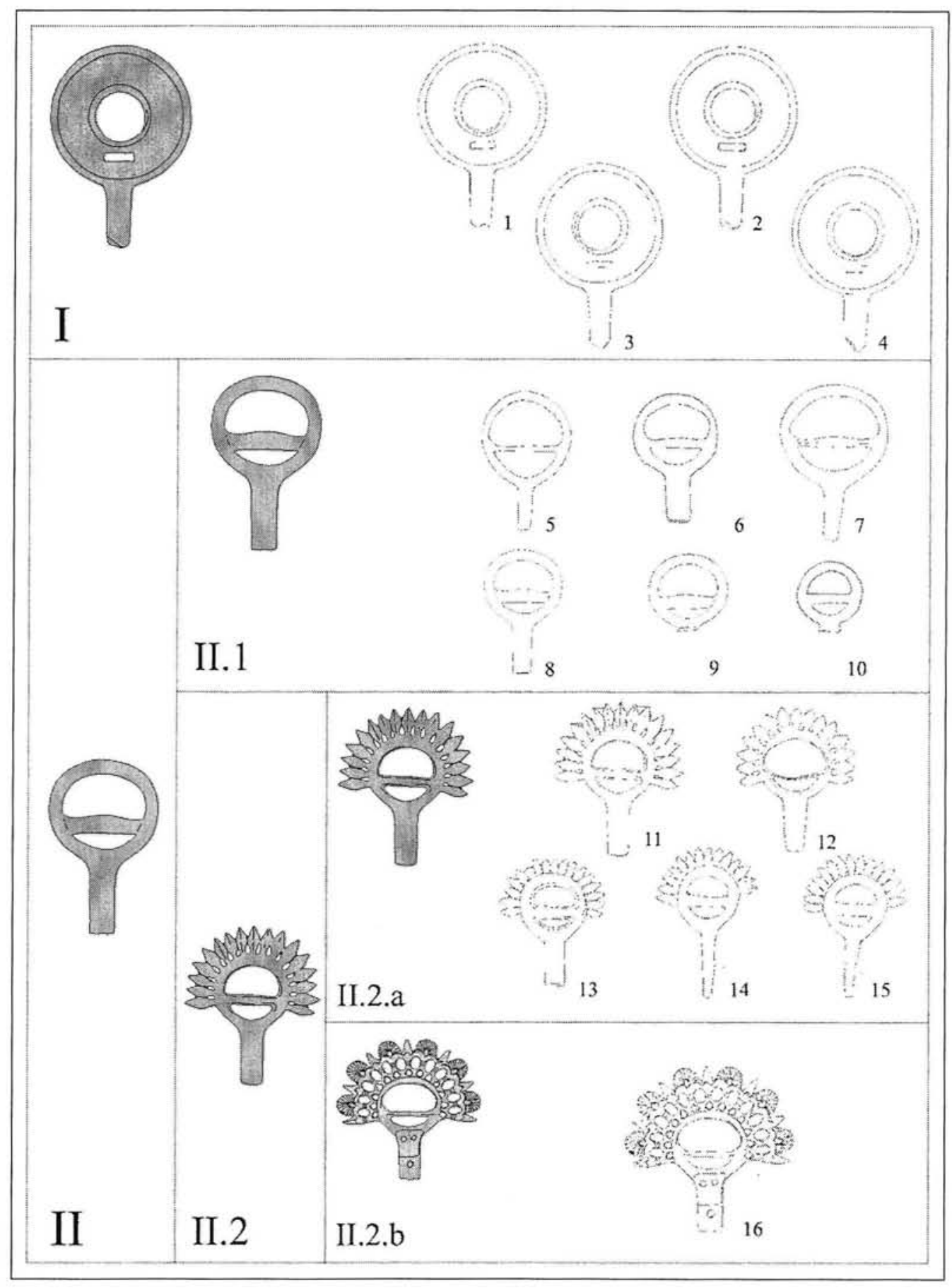

Figura 11.-Tipologia de los pasarriendas de bronce peninsulares. Grupo 1 
Los nuevos pasarriendas recogidos en este estudio componen un nuevo grupo que podemos reconocer como pasarriendas de anilla sencilla y refuerzo o, simplemente como pasarriendas de refuerzo. Se puede dividir este segundo grupo en dos tipos básicos (fig. 12):

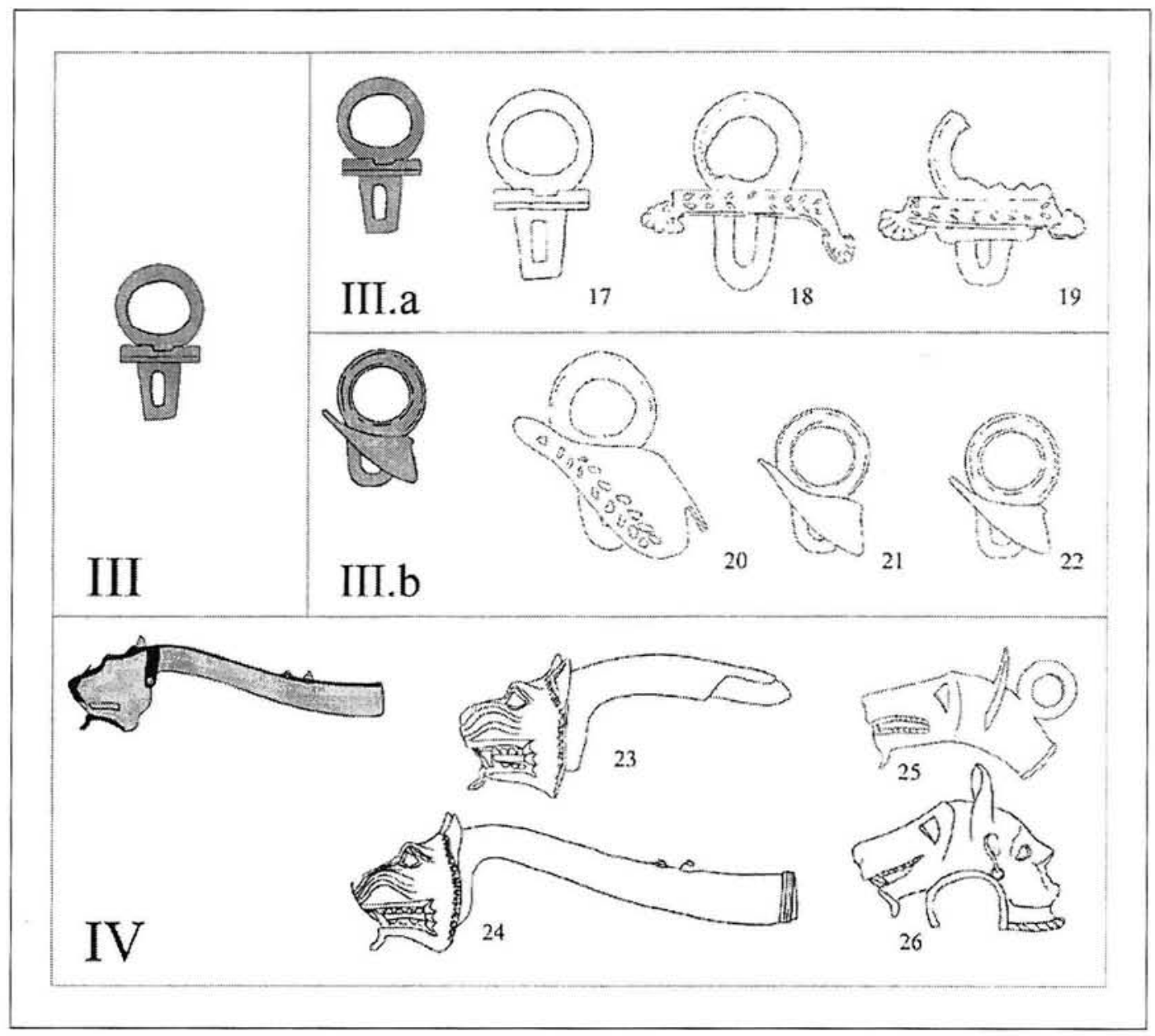

Figura 12.-Tipologia de los pasarriendas de bronce peninsulares. Grupo 2

Tipo III (Cancho Roano): Pasarriendas de refuerzo laminar: formados por anilla con vástago perforado y reforzados por una lámina de bronce que, en función de la disposición que adopte, genera dos variantes: III.a) de refuerzo rectangular curvo, formados por una simple lámina rectangular en disposición horizontal y ligeramente curvada, modalidad a la que se incorporan los pasarriendas de Cancho Roano (cat. 17) y dos del grupo de Ategua (cat. 18-19) y III.b) o pasarriendas de refuerzo en caja donde la lámina curvada da paso a una guarnición aristada que adopta diferentes formas. Se agrupan bajo 
este criterio el tercer pasarriendas de Ategua (cat. 20) y el par de la Dehesa de Alcurrucén (cat. 21 y 22). La presencia de estas dos variantes se debe, como con posterioridad indicaremos, a necesidades de carácter funcional; no son pues motivaciones estéticas ni cronológicas las que justifican la aparición de estas variaciones como, por otra parte, demuestra su asociación en un mismo conjunto. Al igual que los tipos anteriores, el tipo III se puede subdividir atendiendo a diversos criterios como la forma de la guarnición. etc. La presencia de decoración no se tiene en cuenta a efectos tipológicos.

Tipo IV (Mengibar): Pasarriendas de refuerzo zoomorfo: agrupa este tipo los bronces de Máquiz (cat. 23-26) que, dada su condición de objetos escuiltóricos, adquieren conformaciones muy variadas.

Aparte de estos tipos se ha publicado como pasarriendas un fragmento de bronce con anilla procedente de una tumba orientalizante de Estacar de Robarinas (Cástulo) ${ }^{31}$ La anilla es demasiado estrecha para que pase por ella una rienda $(9 \mathrm{~mm}$ de diámetro interior) por lo que esa adscripción es del todo descartable. Más probable es su función como soporte de asas de un recipiente metálico, algo que se ajusta mucho mejor a su tipologia, tal y como originariamente se propuso para este objeto ${ }^{32}$.

\section{Cronología}

Aunque la mayoria de los pasarriendas peninsulares carece de un contexto clarificador, existen elementos de juicio que permiten proponer una cronologia aproximada para los tipos fundamentales $e$, incluso, sugerir una seriación temporal para estos artefactos. Tal vez los ejempiares más antiguos sean los de Alboloduy y La Joya, fechables por sus contextos a principios del siglo VII. La rica tumba onubense viene datándose en la primera mitad del siglo VII a. C. en las más recientes valoraciones. El pasarriendas de El Peñón de la Reina procede de una casa de este poblado correspondiente a su última etapa de ocupación, fechable a finales del siglo ViII y principios del vil a. C., gracias a la presencia de importaciones fenicias de esta época. Es muy poco probable su adscripción a un horizonte anterior. El problema de las guias onubenses es que representan un tipo único, por lo que su cronología no es extrapolable a más casos. Por su parte, el de Alboloduy presenta el inconveniente de que reproduce una modalidad simpie que también está presente en Cancho Roano, en un contexto de finales del siglo $\mathrm{V}$ a. C. (trescientos años posterior), aunque lo más probable es que en el yacimiento pacense constituya una pervivencia. También en estas fechas tempranas del siglo VII a. C. habria que situar el ejemplar del Soto del Hinojar-Las Esperillas pues, sin olvidar que se trata de un hallazgo

${ }^{31}$ Existe cierta confusión en esta adscripción: “...se trata de una abrazadera con un pasarriendas circular perteneciente a un gran lebes de bronce* Ferter, E. y Mancebo, j. (1991): 128, fig. 10.2.

${ }^{32}$ Blanco, A. (1963), con posterioridad: Almagro Basch. M. (1979) 194; Bandera, M.L. de la y Ferrer, E. (1995). 
superficial, las cerámicas halladas en la misma zona del yacimiento apuntan hacia esa cronología.

Es posible que los pasarriendas de cresteria se situien en torno al siglo VII a. C., época de máximo desarrollo de la decoración orientalizante. Esto es particularmente claro en los casos en que la decoración es más puramente fenicia, como ocurre en el ejemplar de la Colección Vives, pero lo más probable es que este tipo alcance el siglo VI, a. C.coincidiendo ya con la aparición de las primeras aristocracias ibéricas, fenómeno al que debe asociarse el conjunto de Úbeda la Vieja que, además, se caracteriza por una inferior calidad técnica en su realización. También durante esta centuria debió usarse el tipo II.1, como puede poner de manif̂esto la pervivencia ya referida de este tipo en Cancho Roano.

Los ejemplares estudiados del tipo III parecen apuntar hacia su uso, fundamentalmente, en el siglo v a. C. Esta es la cronología que cabe señalar para Cancho Roano y, por obvias analogías tipológicas, para el conjunto de Ategua que, según parece, apareció junto a una copa Cástulo con el interior del asa en reserva, lo que, de confirmarse, podría apuntar a las primeras décadas de esta centuria.

Por último, una data del siglo IV a. C. parece que es la que más conviene a la tipología de las piezas de Máquiz y a la iconografía en ellas representada. El desarrollo de la figura del lobo como animal apotropaico por excelencia en el mundo ibérico parece también un fenómeno de la fase plena de esta cultura. A esta fecha apuntan la mayor parte de los trabajos en que se ha estudiado este conjunto, si bien se han manejado otras dataciones más antiguas pero menos probables ${ }^{33}$

En líneas generales parece comprobarse, por tanto, que la seriación tipológica en grupos responde a condicionantes de carácter temporal. De este modo el grupo 1 parece más antiguo, y se fecha, principalmente en los siglos VII y VI a. C., si bien está constatada su pervivencia puntual hasta fines del $\mathrm{V}$ a. C. A esta centuria corresponden los del tipo III -dentro del grupo II- y ya al siglo IV a. C. los pasarriendas del tipo Mengibar Hay que decir, no obstante, que el muestreo con el que contamos es suficientemente escaso como para esperar que futuros hallazgos no alteren o maticen este esquema.

\section{Origen y filiación}

Los pasarriendas del grupo 1 o de vástago constituyen un grupo homogéneo. sin referentes aducibles en otras zonas del Mediterráneo ni de la Europa templada, por lo que deben considerarse una creación genuinamente local. El propio sistema de unión mediante un vástago clavado al arnés por simple presión constituye un recurso peculiar frente a los sistemas de agarre conocidos en otras latitudes; de este modo, los pasarriendas de Urartu se unen con clavos o patillas que se abren ${ }^{34}$ mientras que al-

\footnotetext{
${ }^{33}$ Almagro Gorbea, M. (1987a); Quesada, F. (1997a) 56 propone una data del siglo VI a. C.

${ }^{34}$ Merhav. R. (ed.) (1991) 68.
} 
gunas guias europeas del Hailstatt $C$-simples argollas- parecen ajustarse mediante tiras de cuero ${ }^{35}$.

No obstante esta originalidad, existe una serie de elementos que festonean los yugos de algunos carros próximo-orientales de la Edad del Hierro que. por su parecido con el esquema de las cresterias, pueden conectarse con los pasarriendas peninsulares. Estas piezas en forma de abanico son muy abundantes en Chipre, donde aparecen asociadas a los carros de guerra enterrados en Salamina ${ }^{36}$; algunos se han hallado en Urartu ${ }^{37}$ y también son reconocibles en los relieves nord-sirios ${ }^{38}$ y asirios ${ }^{39}$. Es destacable que todos estos vehículos comparten elementos comunes entre si que permitirian bosquejar un tipo de carro que podriamos denominar asirio o próximo-oriental. Estas piezas se ubicarían a lo largo del yugo (fig. 13.A), en ocasiones conviviendo con verdaderos pasarriendas que adquieren la forma de simples anillas como algunos hallados en Urartu ${ }^{40}$, o como los que aparecen en los carros en miniatura del tesoro de Oxus ${ }^{41}$ Es posible que en la Península se sincretizaran en una sola pieza las guias anulares y los ornamentos flabeliformes de los modelos orientales dando lugar así a los caracteristicos pasarriendas hispánicos.

Otro atributo propio de los pasarriendas peninsulares, el segmento transversal de la anilla, también encuentra eco en territorio oriental, como ya señaiara $W$ Culican al detectar este elemento en un grupo de anillas de arnés procedentes del Luristán, aunque también claramente diferenciables del modelo de pasarriendas con vástago propiamente hispánico ${ }^{42}$. Este segmento merece un comentario adicional pues no es fácil encontrarle explicación funcional. La división de la anilla podria deberse a la existencia de dobles riendas; de hecho existen huellas de desgaste en los dos sectores resultantes en muchos pasarriendas del catálogo. Sin embargo, la existencia de dobles riendas no siempre es fácil de rastrear en la antigüedad, no sólo por el carácter perecedero de los correajes sino por el esquematismo de las representaciones de los tiros de los carros. Algunos ejemplos pueden identificarse, no obstante, en los relieves del Norte de Siria como los de Karchemish. Zincirli, Malatya o Tell Taynat ${ }^{43}$, donde se cuentan claramente dos riendas distintas en el lateral del caballo, lo que nos pone, de nuevo, en conexión con los carros del grupo asirio. Desgraciadamente, en el norte de Siria no se han hallado pasarriendas reales que permitan precisar si estaban compartimentados al modo de los hispánicos.

En suma, lo más probable es que los pasarriendas de vástago hallados en la Península Ibérica constituyan una producción local inspirada en elementos del que podemos denominar carro oriental o asirio y que, por tanto, debieron ser ideados por artesanos

${ }^{35}$ Piggott, S. (1983): fig. 106. En esta fase parecen usarse pasarriendas metálicos en Europa pero por su conformación debian ir en la lanza: (bidem: fig. 110.

${ }^{36}$ Karageonghis, V. (1967) lám. XIVIII, 1-3; 1973-74 láms. LXXVII. LXXXI. CXI y CXXV

${ }^{37}$ Merhav, R. (ed.) (1991): 74-75.

38 Amadasi, M. G. (1965) figs. 15.1, 19.2 y 20.1

${ }^{39}$ Littauser, M. y Crouwel, J.H. (1979)• figs. 53 y 80.

${ }^{40}$ Merhav, R. (ed.) (1991) 68.

4 Littauer, M. y Crouwel. J.H. (1979) fig. 82.

${ }^{42}$ Culicán. W. (1971) lám. IB.

${ }^{43}$ Amadasi, M.G. (1965) respectivamente figs. 16.1, 19.1 19, 2 y 21, 3. 


\section{A}

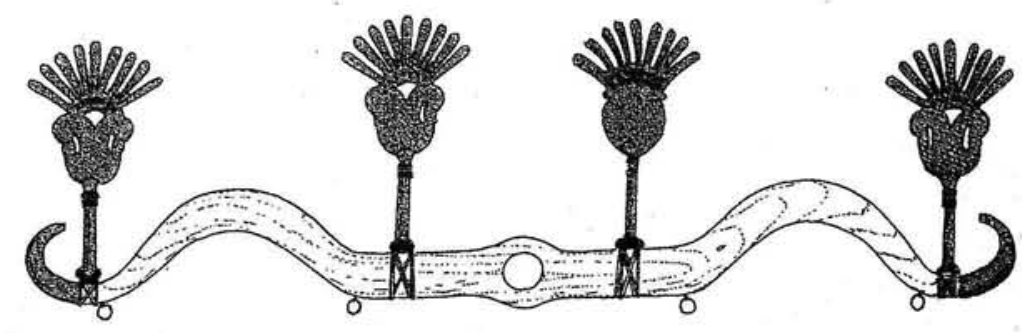

B
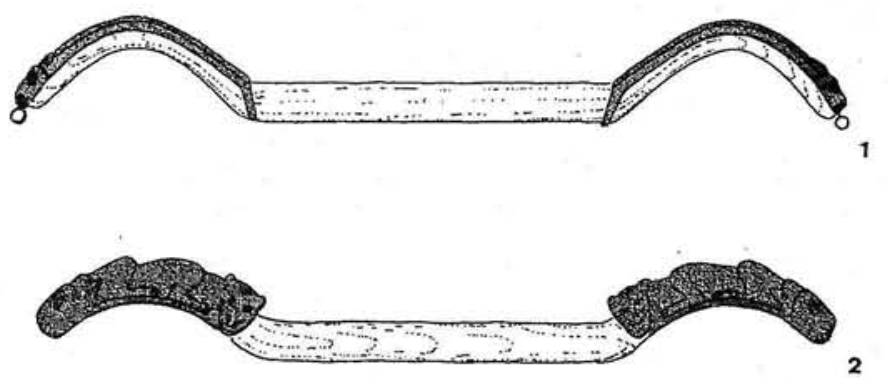

C

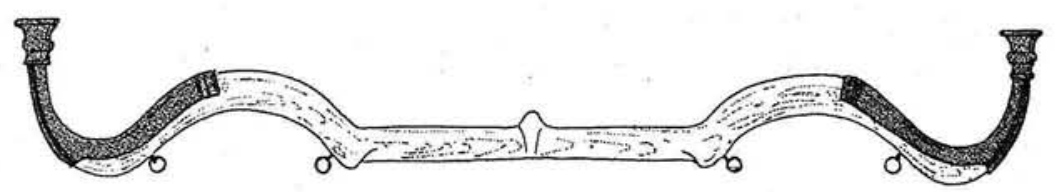

Figura 13.-Reconstrucción de yugos de carros antiguos: A: Salamina de Chipre, s. vIII a. C. (a partir de Karageorghis 1973-1974): B: yugos etruscos de Monteleone di Spoleto (1) y Castel San Mariano (2), siglo VI a. C. (a partir de AAVV 1997); C: Waldalgesheim, Alemania, La Tène Antiguo (según Piggott 1983) 
conocedores de este tipo de vehículos, muy probablemente fenicios trasladados a Occidente. Esto no se opone a las decoraciones que portan un buen número de ellos.

Lo dicho para los pasarriendas de los tipos I y II respecto de su originalidad es aplicable a los de tipo III. para los que tampoco se encuentran referentes válidos allende nuestras fronteras. Por su conformación y por su más reciente cronología, podrían considerarse derivados de los pasarriendas de vástago que se someten a una serie de variaciones significativas: la simplificación de la anilla, que pierde su segmento diametral fenómeno que, de ser cierta la hipótesis anteriormente expuesta, habrá que relacionar con el sistema de tiro- - y la apertura de una ranura vertical en el vástago, posiblemente para mejorar el sistema de sujeción al yugo mediante la inserción de tiras de cuero que podrían, subsidiariamente, agarrar las anillas del enganche, como sugiere la presencia de un aro de hierro adherido a la parte inferior de la placa de uno de los pasarriendas de Ategua (fig. 8). Algunos pasarriendas europeos recuerdan por su concepción al esquema de anilla y refuerzo del tipo Cancho Roano, pero se trata de ejemplares tardíos provistos ya de las decoraciones típicas del periodo de La Tène ${ }^{44}$

Menos originalidad cabe atribuir a los pasarriendas o fundas del tipo IV o Mengibar, ya que existen una serie de elementos en el mundo itálico que pueden identificarse directamente con esta clase de revestimientos y que se pueden conectar por su similitud con las piezas jiennenses. Los más conocidos son los que forran el yugo del carro de Monteleone di Spoleto, expuesto en el Metropolitan Museum de Nueva York desde principios de siglo. Se trata de unas delgadas láminas de bronce repujado con la figuración de dos caras de leones contrapuestos sobre las curvas de los arcos que presentan amplias perforaciones tanto en la boca como en el cráneo ${ }^{45}$. No es posible relacionar estas perforaciones con pasarriendas metálicos porque este elemento no se encuentra de manera habitual entre los restos de carros etruscos, a pesar de que se reconoce el uso de anillas adaptadas a este fin sobre representaciones bidimensionales de ambiente itálico, como es el caso de una larga serie de lastras decorativas realizadas en terracota procedentes de horizontes del siglo VI de varias localidades etruscas. Como cabía esperar, en estos relieves las anillas aparecen instaladas a la altura de los yugos a los que probablemente irian cosidas ${ }^{46}$. También en el vehículo etrusco de Castel San Mariano se han reconocido recientemente forros metálicos de los arcos del yugo, en este caso representando una cabeza leonina y una pantera de cuerpo entero contrapuestos en el mismo bloque ${ }^{47}$, algo que no deja de recordar la disposición bifrontal de las figuras de la pieza $n .{ }^{\circ} 26$ de Máquiz (fig. 13: B.2, fig. 14: C.2). Ambos carros, que se encuentran entre las más desarrolladas creaciones de la broncística etrusca y cuya factura se atribuye a artesanos griegos, se fechan en el siglo vi a. $C$.

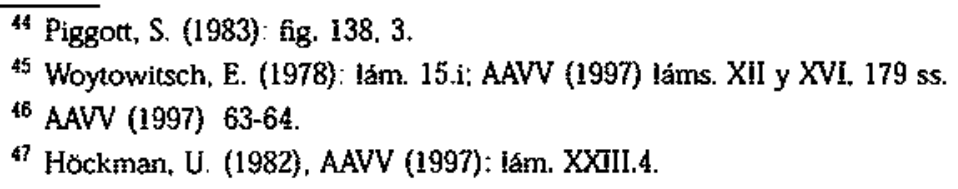


Forros metálicos para los extremos de los yugos aparecen también en algunos carros latenienses (fig. 13: C) ${ }^{48}$ e, incluso, en los carros orientales (fig. 13: A) ${ }^{49}$, pero unos y otros son, por su conformación, mucho más arduamente relacionables con los tipos representadios en el grupo de Mengibar que los mencionados referentes etruscos.

Se constata, pues, una doble influencia para los pasarriendas peninsulares: por un lado la oriental aplicable a los ejemplares más antiguos (siglos VII y VI a. C.) y por otro la etrusca, en los ejemplares fechables ya en los siglos $\mathrm{V} y$, sobre todo, IV a. C.

\section{Función, significado y valoración cultural}

Ya se ha dicho que la función primaria de los pasarriendas es la de hacer de guias de los correajes de las bridas desde el extremo del tiro hasta las manos del auriga. Aunque se ha propuesto su situación en la parte delantera de la caja del vehículo ${ }^{50}$ hay que pensar que, casi con absoluta seguridad, irían sujetos en el yugo de madera, elemento de enganche que debemos postular para todos los carros peninsulares de la Edad del Hierro (fig. 14) Existen varios hechos arqueológicos que permiten verificar esta reconstrucción: 1) el reconocimiento de piezas semejantes en representaciones de carros coetáneos de Úrartu, Asiria, Grecia y Etruria o en los modelos de oro del tesoro de Oxus que ocupan su lugar en el yugo ${ }^{51}$; 2) la ubicación que presentan los pasarriendas hallados en la tumba 17 de La Joya, a ambos lados de la lanza en una situación adelantada y la posición similar que presentan las piezas equiparables halladas en los carros de Salamina de Chipre, a los que con anterioridad nos hemos referido ${ }^{52}$; 3) la situación que ostentan los actuales pasarriendas sobre las colleras rígidas de los coches de caballos que se pueden aún ver en ciudades españolas como Sevilla o Málaga.

Las peculiaridades de los pasarriendas hispanos hacen necesario abundar en los aspectos funcionales, aunque ya nos hemos referido a algunas de estas cuestiones. En primer lugar, los pasarriendas de vástago presentan una característica segmentación en la anilla que se puede relacionar con la presencia de dobles riendas, elemento de tiro documentado en el Norte de Siria a través de los relieves de los palacios neohititas y arameos. También se han hallado anillas segmentadas en el Luristán aunque desprovistas del característico vástago de los pasarriendas hispánicos. Esta costumbre de usar dobles riendas debe desaparecer en los carros peninsulares del siglo $\mathrm{V}$ a. $\mathrm{C}$. En ellos las anillas pasarriendas reducen su tamaño y pierden la segmentación central. Se podría investigar

\footnotetext{
${ }^{48}$ Piggott, S. (1983): fig. 106.

49 Karageorghis, V. (1973-1974); Merhav R.(ed.) (1991): 68-70.

s0 Fernández-Miranda, M. y Olmos, R. (1986): 93.

${ }^{51}$ Merhav, R. (ed.) (1991) 63, fig. 2; para Asizia y Oxus: Littauter, M y Crouwel. j.H. (1979): figs. 55 y 82 respectivamente; para Grecia: Crouwel, J.H. (1992) lám. 11, para Etruria: AAVV (1997): 63-64.

52 Karageorghis, V. (1973-1974): figs. 10-11.
} 


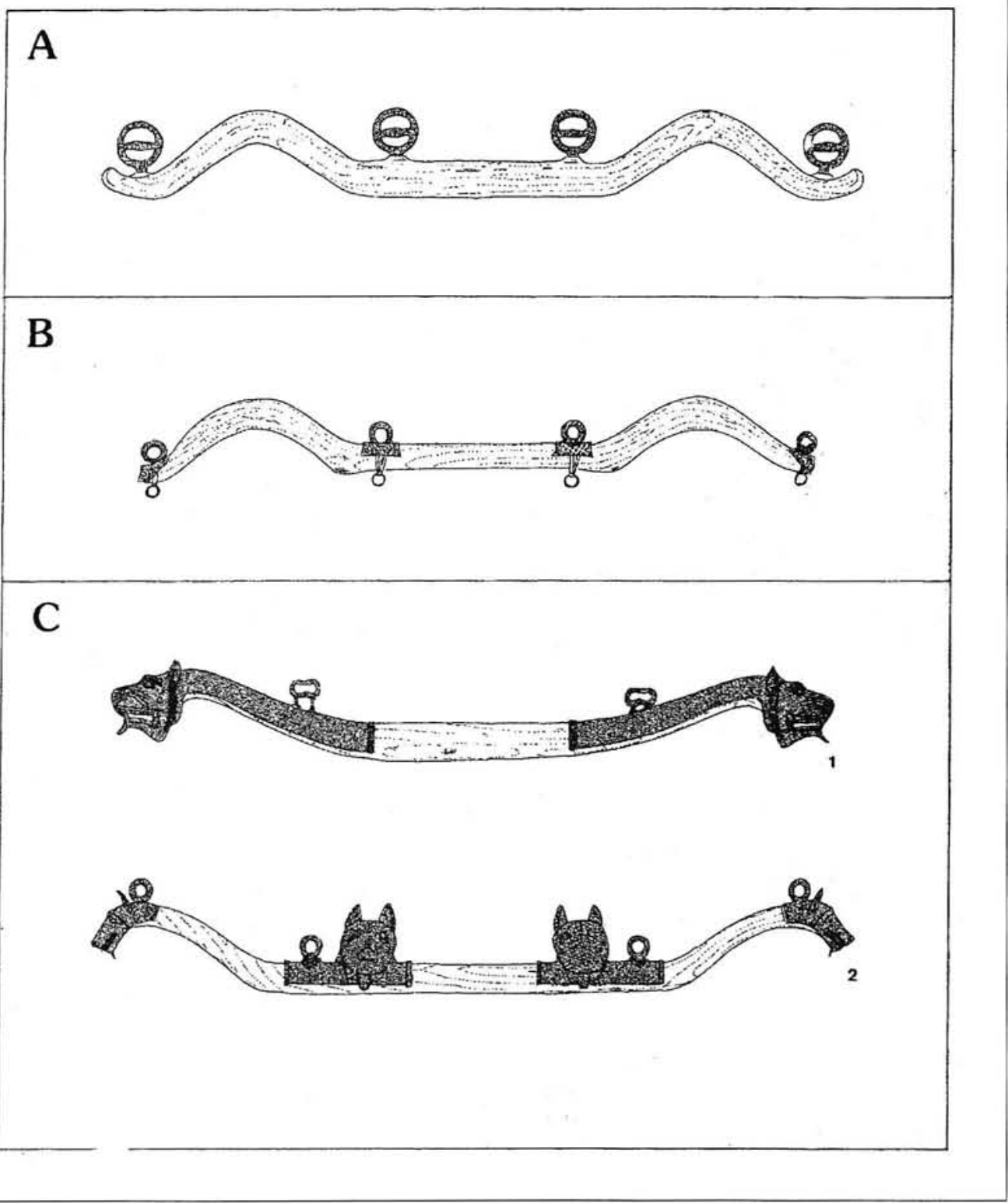

Figura 14.-Reconstrucción de yugos de carros protohistóricos peninsulares con pasarriendas de bronce: A: tipo Alboloduy; B: tipo Cancho Roano; C: tipo Mengibar 
la relación de estas evidencias con posibles modificaciones en los sistemas de control del tiro 0 , incluso, con la introducción de nuevas razas equinas. En este sentido, se puede señalar las diferencias de tamaño de los animales que se derivan de comparar los bocados del siglo Vil a. C. (fundamentalmente los de La Joya, cuyos filetes miden $17 \mathrm{~cm}$ entre las camas) con los del siglo $\mathrm{V}$ a. C. (Cancho Roano, por ejemplo, ha aportado la colección más completa, con ejemplares de en torno a $11-12 \mathrm{~cm})^{53}$; asi como las novedades que algunos de estos ejemplares aportan y que afectan a los procedimientos de control y a los sistemas de monta, por ejemplo la presencia de púas de castigo en los filetes, elemento que. posiblemente haya que poner en relación con el mundo griego ${ }^{54}$, donde frecuentemente aparecen estas puntas ${ }^{55}$ Se trata, en todo caso, de constataciones que requeririan de un estudio más detallado que el que aquí nos proponemos realizar.

Sea como fuere, estos pasarriendas del tipo III incorporan otras novedades funcionales, como la perforación del vástago muy probablemente destinada a pasar por ella (y por una perforación coincidente realizada en las paredes del yugo), una cinta de cuero que permitiría a la vez asegurar el pasarriendas a la madera y sujetar una anilla para enganchar los atalajes del tiro, como parece sugerir la adhesión de un aro de hierro a uno de los pasarriendas de Ategua. La especial configuración de los pasarriendas del tipo III.b debe relacionarse con su situación en el extremo distal del yugo, coincidiendo con las bajadas del arco (fig. 14, B). En el caso del pasarriendas n. ${ }^{\circ} 20$ (procedente de Ategua) esta situación es clara, pues la guarnición está ocluida por la parte más estrecha, excluyendo una posible ubicación en la parte central; los de Pedro Abad podrían instalarse en cualquiera de los bajantes de los arcos del yugo por presentar ambos laterales abiertos. No obstante, el extremo adelgazamiento que presentan en el lado estrecho hace difícil creer que encajaran en otra parte del yugo que no fueran los extremos pues. de otra manera, el brazo central se vería enormemente debilitado. La reconstrucción más viable es, por tanto, la combinación en el mismo yugo de las dos variantes de este tipo, tai y como se deduce de su convivencia en Ategua y tal y como se reconstruye en la figura 14. Los pasarriendas de Pedro Abad han aparecido con unos pasadores de bronce que podrian relacionarse con el sistema de enganchar los caballos al yugo y que, verosímilmente, adoptarian la misma función que cuatro piezas similares en forma de saeta que se documentaron junto con los elementos del arnés del carro en la tumba 17 de La Joya ${ }^{56}$

Pero, sin duda, los objetos que por su forma más fácilmente pueden adscribirse a las guardas de un yugo son las fundas zoomorfas que integran el tipo IV Los iobos de Máquiz presentan la curvatura característica del yugo de un carro (a pesar de ello no sigue habiendo unanimidad a la hora de atribuirles una función y se sigue proponiendo un probable uso como piezas de mueble) Los agujerillos superiores servirían para ajustarlas a la madera mediante clavos y la placa perforada que presentan en su interior debe

\footnotetext{
${ }^{53}$ Para el tema de las tallas ver Baikwill, C. (1973)

54 Jiménez, j. y Gonzälez, A. (1996): 180.

55 Donder, H. (1980)

${ }^{56}$ Gartido. J. P y Orta. E.M. (1978) fig. 48.a-d.
} 
relacionarse con la perforación de los vástagos del tipo III. Las barras fragmentadas que salen de los lomos del lobo completo podrian pertenecer a los pasarriendas propiamente dichos, como ya sugiriera en su dia M. Almagro Basch ${ }^{57}$.

Casi todos los pasarriendas hispánicos acusan en las anillas las profundas huellas que en ellos dejó el roce continuo de las tiras de cuero sometidas a la presión de los caballos y el auriga. Ello viene a demostrar que, a pesar del contexto funerario en que buena parte de ellos han sido hallados, fueron objeto de un intenso uso en vida de sus dueños.

Aparte de su funcionalidad primaria, los pasarriendas de bronce hallados en la $\mathrm{Pe}$ ninsula Ibérica desarrollarian una función secundaria ornamental y simbólica. Los carros más antiguos, los de los siglos VII y VI a. C., complementarian sus yugos con pasarriendas de decoración radial inspirada en algunos elementos propios de los carros orientales. La idea habría sido, muy probablemente, traída a la Península lbérica por los artesanos fenicios. Estas decoraciones unidas a otros elementos simbólicos, como los leones que flanquean las ruedas del carro de la Joya, irian destinadas a subrayar el prestigio y el estatus del poseedor del vehículo con conceptos propios de la ideología oriental como las decoraciones florales o los animales "fantásticos" que conectan al individuo sociaimente destacado con el mundo mítico del más allá, al tiempo que desarrollan una función protectora.

Este tipo de referencias parece ser sustituida en los carros del siglo IV a. C. por elementos formalmente tomados del mundo itálico pero ideológicamente imbricados en la propia tradición ibérica: los forros de Máquiz recuerdan por su disposición refuerzos similares de los carros de Monteleone y Castel San Mariano, pero el uso de un animal propiamente ibérico como el lobo, relacionable con planteamientos ideológicos de corte heroico, habla de las transformaciones a que fueron sometidos los modelos foráneos por parte de los artesanos locales.

En suma, el análisis de los pasarriendas de bronce de la protohistoria hispánica se hace eco de dos tendencias culturales que ya se apreciaban con carácter global al estudiar el desarrollo histórico de la Primera Edad del Hierro en el Mediodía Peninsular y que, en este caso, cabe aplicar al estudio de los carros: por un lado la existencia de una fase antigua fechable en los siglos VII y VI a. C. donde son palpables las influencias orientales. La dispersión de items en este momento (fig. 15) es netamente suroccidental, a pesar de que la distribución geográfica de los pasarriendas no es de las más elocuentes. Por otro lado, a partir del siglo VI a. C. se evidencia la penetración de elementos grecoitálicos que se observan en otros aspectos relacionables de la cultura ibérica, como el armamento $^{58}$ La mayor parte de los hallazgos de esta época se verifican ahora en el Alto Guadalquivir, coincidiendo con el desarrollo de los principados ibéricos. El esquema general está sometido a variaciones que la continuación de las investigaciones sobre el carro protohistórico en la Península Ibérica permitirá conocer mejor y matizar. Los hallazgos de Cancho Roano se hacen eco de la coexistencia en un mismo horizonte (probablemente en un mismo vehículo) de dos generaciones de pasarriendas.

${ }^{57}$ Almagro Basch, M. (1979)

${ }^{58}$ Kurtz, W.S. (1991): Quesada, F (1997ל) 127 


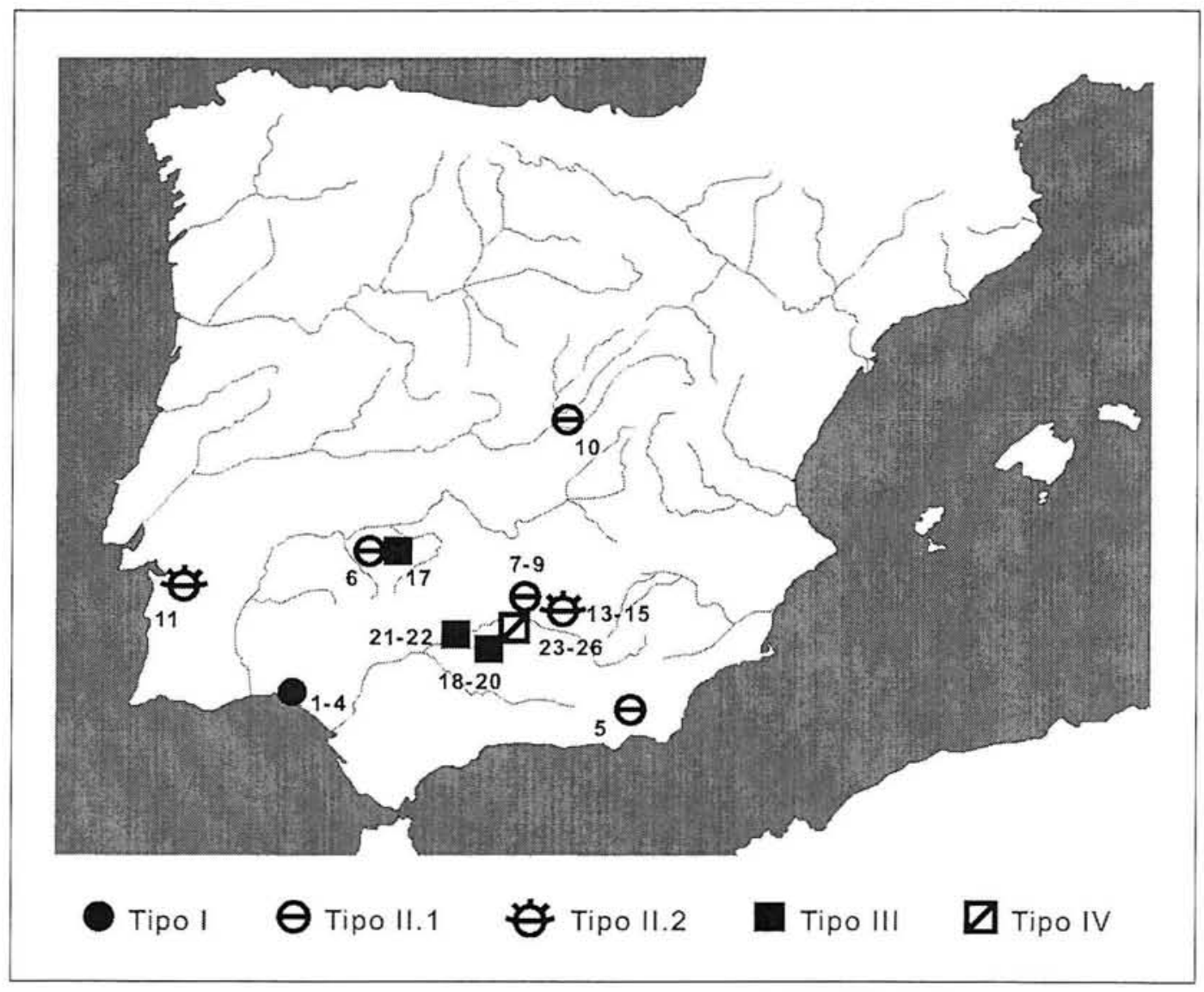

Figura 15.-Distribución de los pasarriendas de bronce en la Península Ibérica

También evidencian el lujo y la riqueza que alcanzaron los aristócratas de la Cuenca Media del Guadiana a finales del siglo V a. C. y las intensas relaciones que los unían con los príncipes ibéricos de la Alta Andalucía, algo que ya se han señalado en otras ocasiones $^{59}$ y que ahora vienen a reforzar las fuertes semejanzas que presentan los componentes metálicos del carro de Ategua con los restos hallados en Cancho Roano. Por su parte, el pasarriendas del Soto del Hinojar-Las Esperillas refleja la intensidad de los contactos entre las poblaciones meridionales y meseteñas del Hierro Antiguo, a las que también aluden otros hallazgos de reciente valoración que se añaden a los ya conocidos de Las Herencias, El Carpio, Las Fraguas y otros del Occidente de Toledo ${ }^{60}$. Nos referimos a la vasija con incrustación de botones de bronce de Camino de los Pucheros $1^{61}$ y

\footnotetext{
${ }^{59}$ Celestino, S. y Jiménez, J. (1993); Jiménez, J. (1997).

${ }^{60}$ Fernández-Miranda, m. (1986); Fernández-Miranda, M. y Pereira, J. (1992).

${ }^{61}$ Muñoz, K. (1993): fig. 7. 12.
} 
el vaso con decoración de lotos incisos, el soporte de carrete, la cazuelita o remate de timiaterio y la casa de esquinas redondeadas de Puente Largo de Jarama ${ }^{62}$; todos ellos. como el hallazgo del Soto, procedentes de contextos de la comarca de Aranjuez, en el Tajo Medio, vinculados a importantes vados y confluencias de vías naturales de comunicación ${ }^{63}$

Hay un hecho que no pasa inadvertido en el estudio de los conjuntos de pasarriendas de bronce de la Edad del Hierro peninsular y es que raramente aparecen vinculados a elementos de carro que no correspondan al tiro. Salvo el excepcional hallazgo de la tumba 17 de La Joya y el incierto ejemplar de Alcácer do Sal, que apareció en una necrópolis en la que también se hallaron elementos de ruedas ${ }^{64}$, los conjuntos que conocemos se limitan a ofrecernos partes del yugo y de la brida. Contando, evidentemente, con las limitaciones que impone la naturaleza de la información, tal sucede en Cancho Roano, Úbeda la Vieja, Ategua y también en Máquiz. Especialmente significativo es el caso de Cancho Roano, por proceder los datos de una excavación arqueológica y por tratarse de un edificio de especiales características. Es muy difícil pensar que en un espacio como la habitación H-8 de Cancho Roano hubiese un carro completo, ni siquiera desarmado, aunque alguna vez así se haya señalado ${ }^{65}$. Siendo todos los elementos allí presentes integrantes del yugo y la brida, es posible que esta habitación, en la que se han recogido otros objetos de prestigio y rituales como la base de un jarro de bronce, hubiese un yugo ricamente adornado como símbolo sincrético de la posesión de un carro y del significado social que ello comporta, en un espacio en el que, presumiblemente, estarian expuestos un gran número de símbolos marcadores de rango.

Es posible que esta sinécdoque simbólica también tuviera lugar en el mundo ibérico desde el siglo VI al iv a. C. y que en esta época el yugo per se se convirtiese en un indicador de rango que acompañara, desprovisto del resto del carro, a su dueño en su última morada. La hipótesis debería ser contrastada con una cantidad y, sobre todo, con una calidad de las evidencias arqueológicas mucho mejores que las que en la actualidad poseemos, sin embargo, aunque difusos, los datos parecen apuntar en la dirección de un uso individualizado de los yugos -obviamente desmontables - con carácter simbólico en esta fase de la protohistoria hispánica.

Mediado el siglo IV a. C. , hallazgos como los de Toya o Baza demuestran que en esta época se volvió a la ancestral costumbre de depositar carros completos en las ricas tumbas del horizonte Ibérico Pleno. Ahora ya, coincidiendo con la dimensión militar de las nuevas aristocracias aitoandaluzas, realizados con elementos de hierro ${ }^{66}$

\footnotetext{
62 Muñoz, K. y Ortega, J. (1997)

63 Un modelo que se repetirá durante la Segunda Edad del Hierzo (Muñoz, K. y Madrigal, A. 1999)

${ }^{64}$ Schüle. W. (1969) láms. 106-107

${ }^{65}$ Ruiz. A. y Molinos, M. (1993): 185.

${ }^{66}$ Fernández Miranda. M. y Olmos, R. (1986)
} 


\section{RESUMEN Y CONCLUSIONES}

En el yacimiento del Soto del Hinojar-Las Esperillas (Aranjuez, Madrid) apareció un pasarriendas de bronce que, pese a constituir un hallazgo absolutamente excepcional en el ámbito de la Cuenca Media del Tajo y aún de la Meseta Sur, pertenece a un tipo bien reconocido en la Península Ibérica formado por una anilla segmentada y un vástago de inserción vertical. El contexto cerámico de superficie que acompañaba a la pieza en el sitio arancetano permite fecharla en torno al siglo VII a. C., siendo verosímil asímismo, que procediera de una estructura habitacional arrasada que no pudo documentarse mediante excavación.

El hallazgo de este nuevo ejemplar y el reconocimiento como pasarriendas de una serie de objetos con aros o anillas procedentes de varios yacimientos meridionales, justifica un estudio de conjunto de estos elementos de carro protohistóricos.

Desde el punto de vista tipológico se pueden establecer dos grupos, uno integrado por el tipo descrito y ya reconocido por la investigación. formado por un vástago y anilla segmentada y un nuevo grupo de pasarriendas de anilla simple y refuerzo laminar, subdivisible en varios tipos. Este segundo grupo alberga unidades procedentes de Cancho Roano (Zalamea de La Serena, Badajoz), Ategua y Pedro Abad (Córdoba), si bien estas últimas proceden de actividades ilícitas, por lo que los datos no son del todo seguros. También se han unido a este grupo los forros metálicos de Máquiz, decorados con prótomos figurados, y se propone para ellos una reconstrucción en el yugo de los carros, sujetando pasarriendas.

La división tipológica parece responder a criterios cronológicos. De este modo, los pasarriendas del grupo 1 serian más antiguos, pudiendo fecharse entre los siglos VII y VI a. C., mientras que los del grupo 2 deben situarse ya en los siglos $\mathrm{V}$ y IV a. C., aunque se constatan significativas pervivencias. Por otro lado, las caracteristicas morfológicas de estos útiles permiten observar en ellos una doble infuencia, oriental para los del grupo 1. que estarían inspirados en elementos de los carros chipriotas y del grupo asirio, y etrusca para los más reclentes del grupo 2, particularmente para los forros zoomorfos, que hallan buenos referentes en los famosos vehículos italianos de Monteleone di Spoleto y Castel San Mariano. A pesar de estos influjos, se trata en todos los casos de objetos bien tipificados que no cuentan con paralelos exactos fuera de la Península Ibérica por lo que, en última instancia, deben tenerse por creaciones penirisulares. Esta secuencialidad cultural debe relacionarse con la propia evolución que experimentara el carro ligero en la Península Ibérica a lo largo de la Protohistoria y también con el desplazamiento de las áreas de máximo desarrollo cultural del Suroeste tartésico al Sureste ibérico a lo largo del siglo VI a. C.

Los pasarriendas de bronce se instalarían en los yugos de los carros, uniendo a su función primaria como guías para las bridas un componente decorativo y simbólico conferido por su naturaleza broncínea y por la decoración que portan muchos de estos objetos. De este modo se agregarían a otros elementos de los carros (piénsese en los leones de La Joya) como marcadores de la preeminencia social de los régulos tartésicos y de 
los aristócratas ibéricos que los poseyeron. Los fieros animales representados en los vehículos adquiririan un valor profiláctico, siendo destacable también la sustitución del león orientalizante por el lobo ibérico. En otras zonas como Extremadura o La Meseta se constata igualmente la presencia de carros ligeros decorados con atalajes de bronce. En Cancho Roano parece clara su asociación a individuos socialmente destacados que unirían el uso del carro a un aparato ceremonial heredero del Periodo Orientalizante. En el Soto del Hinojar-Las Esperillas esta deducción es más problemática, si bien recientes datos $^{67}$ vienen a poner de manifiesto la existencia de élites sociales que adoptan desde época temprana elementos simbólicos procedentes del Mediodia Peninsular.

De los contextos reconocidos parece deducirse que durante los siglos vi y $\mathrm{V}$ a. $\mathrm{C}$. los yugos de los carros adquirieron un valor simbólico per se, siendo muy posible que estos elementos, ricamente guarnecidos, se exhibieran como signo de estatus en espacios destinados a la epifanía áulica, y que pasaran a formar parte de los ajuares funerarios sin incorporar el resto del vehículo. Esto contrasta con lo observado en el Periodo Orientalizante Pleno, donde los carros acompanan en su integridad a los difuntos, tal y como se observa en La Joya y como puede desligarse de los restos de Alcácer do Sal. Los hallazgos ibéricos de Toya o Baza se hacen eco de que, a partir del siglo IV a. C., volvió a recuperarse esta costumbre de depositar vehículos completos, ahora ya carros de guerra guarnecidos de un metal nuevo: el hierro.

\section{BREVE CATÁLOGO DE PASARRIENDAS DE BRONCE DE LA PENINSULA IBÉRICA (*)}

1-4.--Pasarriendas de La Joya (Huelva). Museo de Huelva 2744-2747.

Cuatro pasarriendas de bronce con vástago rectangular de tipo discoidal. $\mathrm{H}$ : en torno a $15 \mathrm{~cm}$. $\varnothing: 10,5 \mathrm{~cm}$. Peso: 222, 216,5; 224 y $224 \mathrm{~g}$ respectivamente.

Proceden de la tumba 17 de La Joya (Huelva) donde fueron hallados junto al refuerzo de lanza de un carro y otros elementos de arreos ecuestres, algo adelantados a la propia caja del vehiculo. Contexto: primera mitad del siglo vII a. C.

Bibliografia: J. P. GarRido y E. M. ORTA, 1978; A. EsCalERA, 1978; M. Almagro BASCH, 1979; M. FERNÁNDEZ-MIRANDA y R. OlMOS, 1986; E. FERRER y J. MANCEBO, 1991.

5.-Pasarriendas de El Peñón de La Reina (Alboloduy, Almería). C. Martinez.

Pasarriendas de bronce con vástago rectangular del tipo de anilla simple. $\mathrm{H}: 11,4$ $\mathrm{cm} ; \varnothing: 7,4 \mathrm{~cm}$.

Apareció en las excavaciones del poblado del Peñón de la Reina, en la llamada casa 3 , cuya última ocupación se fecha a finales del siglo Vil y principios del VII a. C., coincidiendo con las primeras importaciones fenicias.

Bibliografia: C. MARTíneZ y M C. BoteliA, 1980; E. FerRer y J. MANCEBo, 1991.

${ }^{67}$ Muñoz, K. (1999a: 1999b). 
6.-Pasarriendas de Cancho Roano (Zalamea de La Serena, Badajoz) Museo Arqueoíógico Provincial de Badajoz 10.693.

Pasarriendas de bronce con vástago rectangular del tipo de anilla simple. H: 8,5 $\mathrm{cm} ; \varnothing: 6,5 \mathrm{~cm}$; peso: $101 \mathrm{~g}$.

Se halló en la parte externa al edificio principal por su lado sur. Podría proceder de los arrastres de las habitaciones de este ala del edificio. Contexto: finales del siglo v a. C.

Bibliografía: J. MALUQuer, 1983; E. FERRER y J. MANCEBO, 1991.

7.9.-Pasarriendas de Cástulo (Linares, Jaén). Colección Alhonoz (Herrera, Sevilla) s/n.

Tres pasarriendas de bronce con vástagos diversos (perdido en un caso) del tipo de anilla simple. $\mathrm{H}: 12,8 ; 10$ y $6.5 \mathrm{~cm} ; \varnothing: 8.5 ; 6.5$ y $6.5 \mathrm{~cm}$, pesos: $198 ; 109$ y $77 \mathrm{~g}$ respectivamente.

Proceden de actividades ilegales realizadas, al parecer, en el entorno de Cástulo. Se desconoce el contexto.

Bibliografia: E. FERRER y J MANCEBO, 1991

10.-Pasarriendas del Soto del Hinojar-Las Esperillas (Aranjuez, Madrid). Consejería de Educación y Cultura, Comunidad de Madrid.

Pasarrienđas de bronce con vástago fragmentado del tipo de anilla simple. $\mathrm{H}$ : 5.5 $\mathrm{cm} ; \varnothing: 5 \mathrm{~cm}$.

Procede de prospecciones superficiales del yacimiento del Soto del Hinojar-Las Esperillas (Aranjuez)en unas zonas de grandes manchas de ceniza con materiales cerámicos de la Primera Edad del Hierro (siglo vII a. C.)

Inédito.

11.-Pasarriendas de Alcácer do Sal (Portugal) Museu Nacional de Arqueologia e Etnologia (Lisboa) 11.244/OSM 789.

Pasarriendas de bronce de vástago rectangular y anilla de crestería simple calada. $\mathrm{H}: 12,6 \mathrm{~cm} ; \varnothing: 6 \mathrm{~cm}$; peso: $240 \mathrm{~g}$.

Procede de la necrópolis del Olival do Senhor dos Mártires, Alcácer do Sal (Setúbal, Portugal), donde se realizaron excavaciones durante el siglo XIX. Se desconoce el contexto concreto.

Bibliografía: W. SCHULle, 1969; M. ALMAGRo BASCH, 1979; M. FERNANDEZ MIRANDA y R. OIMOS, 1986; E. FERRER Y J. MANCEBO, 1991.

12.-Pasarriendas del Museo de Barcelona. Museo Arqueológico de Barcelona 11580.

Pasarriendas de bronce de vástago rectangular y anilla de crestería simple calada. H. $11,7 \mathrm{~cm} ; \varnothing: 6 \mathrm{~cm}$; peso: $168 \mathrm{~g}$.

Se ignoran su procedencia y contexto.

Bibliografia: M. ALMAGRO BASCH, 1979; M. FERNÁNDEZ-MiRANDA y R. OlMOS, 1986; E. FERRER y J. MANCEBO, 1991. 
13-15.-Pasartiendas de Úbeda La Vieja (Jaén). Colección Alhonoz (Herтегa, Sevilia) $s / n$.

Tres pasarriendas de bronce de vástago rectangular (13) y apuntado de sección cuadrada (14 y 15) con anilla de cresteria simple sin calar. $\mathrm{H}: 10,2 ; 11,5 ; 12,5 \mathrm{~cm} ; \varnothing: 5,5$; 5.3; $5,5 \mathrm{~cm}$; peso: $207 ; 176$ y $173 \mathrm{~g}$ respectivamente.

Proceden de actividades ilícitas realizadas, al parecer, en torno al poblado ibérico de Úbeda la Vieja. Se hallaron junto a dos bocados de bronce de camas discoidales y un conjunto de botones que podría fecharse en torno al siglo VI a. $\mathrm{C}$.

Bibliografia: E. FERRER y J. MANCEBO, 1991.

16.-Pasarriendas de la Colección Vives. Hispanic Society of America (Nueva York) R-4509.

Pasarriendas de bronce de vástago rectangular reforzado con placas remachadas del tipo de crestería compleja calada a base de palmetas y capullos cerrados. $\mathrm{H}: 13,2 \mathrm{~cm}$; peso: $283,5 \mathrm{~g}$.

Se ignoran los datos sobre su procedencia y su contexto. Fue adquirida en Sevilla, lo que podría indicar un origen andaluz que, vistas las caracteristicas formales del objeto. resulta lo más probable. La decoración es propia del siglo VII a. C.

Bibliografía: A. GARCIA Y BELLIDO, 1970; W. CULICAN, 1971; J. M. BLAZZQUEZ, 1975; M. Almagro Basch, 1979; M. FERnANDEZ-Miranda y R. Olmos, 1986; E. FerRer y J. MAN. CEBO, 1991; A. GARCIA Y BELLIDO y M. P. GARCfA-BELLIDO, 1993.

17.-Pasarriendas de Cancho Roano (Zalamea de La Serena, Badajoz). Museo Arqueológico Provincial de Badajoz 10.722.

Pasarriendas de bronce de refuerzo laminar simple y liso con dos perforaciones cuadradas en la lámina. $\mathrm{H}: 8,8 \mathrm{~cm} ; \varnothing 4,8 \mathrm{~cm}$. Peso: $193 \mathrm{~g}$.

Procede de la Habitación $\mathrm{H}-8$ de Cancho Roano. Contexto de finales del siglo v a. C.

Bibliografia: J. MALUUQUER, 1983.

18-20.-Pasarriendas de Ategua (Córdoba). Colección Alhonoz (Herrera Sevilla) s/n.

Tres pasarriendas de bronce de refuerzo laminar simple (18 y 19) y de cajetín (20). Están decorados con palmetas e impresiones foliáceas. $H: 7,5 ; 7$ y $8 \mathrm{~cm} ; \varnothing: 4,5 ; 4$ y $4 \mathrm{~cm}$; peso: $157 ; 160$ y $226 \mathrm{~g}$ respectivamente.

Proceden de actividades ilegales realizadas, al parecer, en el entorno del poblado de Ategua donde se hallaron junto a un conjunto de bronces, una urna ibérica pintada y una copa griega de barniz negro fechables en la primera mitad del siglo $\mathrm{V} \mathrm{a}$. $\mathrm{C}$.

Inéditos.

21-22.-Pasarriendas de Dehesa de Alcurrucén (Pedro Abad, Córdoba). Colección Alhonoz (Herrera, Sevilla) $s / n$.

Dos pasarriendas de bronce de refuerzo de cajetín abierto. $\mathrm{H:} 6 \mathrm{~cm}: \varnothing: 4 \mathrm{~cm}$; peso: 77 y $89 \mathrm{~g}$ respectivamente. 
Proceden de actividades ilegales en la Dehesa de Alcurrucén (Pedro Abad, Córdoba), donde fueron hallados con restos de cenizas y dos pasadores. Se desconocen otros elementos del contexto.

Inéditos. $54 / 2$.

23-24.-Fundas zoomorfas de Máquiz (Mengibar, Jaén). M. A. N. 1970/54/1; 1970/

Dos fundas de bronce con prótomos zoomorfos representando cabezas de lobos y decoración grabada. Long. 40 y $53 \mathrm{~cm}$ respectivamente.

Aparecieron junto con las piezas 25 y 26 en el Cortijo Máquiz (Mengibar, Jaén) en 1860. Por su decoración pueden fecharse en el siglo iV a. C.

Bibliografía: M. ALMAGRo BASCH, 1979; M. FERNÁNDEZ-MiRANDA y R. OlMOS, 1986; M. AlMAGRO-GORBEA, 1987; O. JAEGGI, 1992; E. RUANO, 1992.

25-26. -Fundas zoomorfas de Máquiz (Mengibar, Jaén). Real Academia de la Historia (Madrid); 178 y 179.

Dos fundas de bronce con decoración figurada, una de ellas en forma de cabeza de lobo con anilla en la región occipital y la otra con cabeza de lobo contrapuesta a cara humana con torques, conserva el arranque de una posible anilla. Long. 22, 2 y $21,5 \mathrm{~cm}$; peso 1.647 y $2.211 \mathrm{~g}$, respectivamente.

Aparecieron junto con las piezas 23 y 24.

Bibliografía A. DE los Rfos, 1909; C. MillÁN y G. DE LA CHICA, 1958; M. Almagro BASCH, 1979; E. FERRER y J. MANCEBO, 1991; O. JAEGGI, 1992.

(*) El orden del catálogo coincide con la numeración de las figuras 11 y 12 .

\section{BBLIOGRAFIA}

AAVV (1997): Carrl da guerra e principi etruschi, Roma.

ALMAGRO BASCH, M. (1979): "Los origenes de la toréutica ibérica", TP 36, pp. 174-208.

AlMAGro GORBEA, M. (1987): "Origen y significado de la escultura ibérica", Escultura lbérica. pp. 48-67.

AlMAGRo GORBEA, M.; DOMfNGUEZ, A., y LOPEZ-AMBITE, F. (1990): "Cancho Roano. Un palacio orientalizante en la Península Ibérica", MM 31. pp. 251-308.

ALmaGro GoRBEA, M., y Fernández-Galiano. D. (1980): Excavaciones en el Cerro Ecce Homo (Alcalá de Henares, Madrid). Arqueología 2, Madrid.

AMADASI, M. G. (1965): L'iconografia del carro di guerra in Siria e Palestina, Roma.

BALKWILL, C. (1973): "The Earliest Horse-bits of Western Europe", PPS 39, pp. 425-452.

BANDERA, M. L. de la, y FERRER, E. (1995): "Reconstrucción del ajuar de una tumba de

Cástulo: ¿Indicios de mestizaje?", Kolaios 4, pp. 53-65. 
Blanco, A. (1963): "El ajuar de una tumba de Cástulo", AEspA XXXVI, pp. 40-69.

BlasCo, M. C., y BAENA. J. (1989)- "El yacimiento de La Capellana (Pinto, Madrid). Nuevos datos sobre las relaciones entre las costas meridionales y la Submeseta Sur durante la Primera Edad del Hierro", CuPAUAM 16, pp. 211-231.

Blasco, M. C.; CAlle, J., y SANCHEZ-CAPILlA, M. L. (1991): "Yacimiento del Bronce Final y de Época Romana en Perales del Río (Getafe, Madrid)", Arqueología, Paleontología y Etnografia 1. pp. 37-147

BLASCO, M. C.; LUCAS, M. R. y Alonso, M. A. (1991): "Excavaciones en el poblado de la Primera Edad del Hierro del Cerro de San Antonio". Arqueología, Paleontología y Etnografia 2, pp. 9-88.

Blasco, M. C., SÁnCHeZ-CAPILla, M. L., y CAlle, J. (1988): "Madrid en el marco de la Primera Edad del Hierro de la Península İbérica", CuPAUAM 15, pp. 139-182.

BLÁZQUEZ, J. M. (1975): Tartessos y los origenes de la colonización fenicia en Occidente, Salamanca (2. $\left.{ }^{3}\right)$.

Celestino. S., y JIMÉnez, J. (1993). El Palacio-Santuario de Cancho Roano IV. El Sector Norte, Badajoz.

Crouwel, J. H. (1987): "Chariots in Iron Age Cyprus", RDAC, pp. 101-118.

- (1990) "A Chariot from Salamis newly reconstructed", RDAC, pp. 101-105.

-. (1992): Charriots and other Wheeled Vehicles in Iron Age Greece, Amsterdam.

Culican, W. (1971): "A Phoenician Bronze from Spain”, AEspA 44, pp. 156-160.

Delibes, G.; Fernández Manzano, j., y Rodríguez, J. A. (1990): "Cerámica de la plenitud de Cogotas I: el yacimiento de San Román de la Hornija (Valladolid)", Boletín del Seminario de Estudios de Arte y Arqueología LVI, pp. 51-70.

DONDER, H. (1980): Zaumzeug in Griechenland und Cypern, PBF XVI, 3. Munich.

ESCALERA, A. (1978): "Examen de laboratorio de los materiales de cLa Joyas (Huelva)", EAE 96, pp. 213-256.

FERNÁNDEZ-MIRANDA, M. (1986) " "La estela de Las Herencias (Toledo)", Estudios en homenaje al Dr. Antonio Beltrán Martínez, pp. 463-476.

FERNÁNDEZ-MiRANDA, M., y Olmos, R. (1986): Las ruedas de Toya y el origen del carro en Ia Península Ibérica, Madrid.

FERnÁNDeZ-Miranda, M., y PEREIRA, J. (1992): "Indigenismo y orientalización en la tierra de Talavera", Actas de las Primeras Jornadas de Arqueologia de Talavera y sus tierras, Toledo, pp. 57-94.

FERRER, E., y MANCEBO, J (1991): "Nuevos elementos de carros orientalizantes en le Aita Andalucía. Algunas precisiones en torno a su función, significado y distribución", CUPAUAM 18, pp. 113-148.

GARCIA Y BELLIDO, A. (1970): "Algunas novedades sobre la arqueologia púnico tartessia", $A E s p A 43$, pp. 3-49. 
Garcfa y Bellido, A., y Garcia-Bellido, M. P (1993) Album de dibujos de la Colección de bronces antiguos de Antonio Vives Escudero, Anejos de AEspA XIII. Madrid.

GARRIDO, J. P., y ORTA, E. M., (1978): Excavaciones en la necrópolis de «La Joyà (Huelva) II. $\left(3 .^{2}, 4 .^{2} y 5{ }^{2}\right.$ campañas), EAE 96.

HöCKMAN, U. (1982). Die Bronzen aus den Fürstengrafe von Castel San Mariano, Antikensammlungen München. Katalog der Bronzen 1, Munich.

JAEGGr, O. (1992): Vier Iberische Bronzen aus Maquiz, Mengíbar (Jaén). Basilea. (Memoria de Licenciatura inédita).

JIMENEZ, J. (1997): "Cancho Roano y los complejos monumentales post-orientalizantes del Guadiana", Complutum 8, pp. 141-159.

JMMÉNEZ. J., y GONZALEZ, A. (1996): "Broncística y poblamiento en la Alta Extremadura: a partir de unos materiales de El Risco (Sierra de Fuentes, Cáceres)", Zephyrvs XL, pp. 169-189.

KARAGEORGHiS, V. (1967) - Excavations in the Necropolis of Salamis I. Nicosia.

- (1973-1974): Excavations in the Necropolis of Salamis III, Nicosia.

KURTZ, W. S. (1991). "Elementos etrusco-itálicos en el armamento ibérico", La Presencia de Material Etrusco en la Península Ibérica (J. Remesal y O. Musso eds.). Barcelona, pp. 187-196.

LiTTAUeR, M., y CROUWEL, J. H. (1979): Wheeled Vehicles and Ridden Anjmals in the Ancient Near East, Leiden.

LOPEZ, L.; MADRIGAL, A.; MUNOZZ, K., y ORTIZ, J. R. (1999) 'La transición Bronce FinalEdad del Hierro en la cuenca media del Tajo: el yacimiento de Camino de las Cárcavas (Aranjuez, Madrid)", en R. de Balloin y P Bueno (eds.), II Congreso de Arqueología Peninsular (Zamora, 1996), Zamora, tomo III, pp. 141-152.

MALUQUER DE MOTES, J. (1981): El santuario protohistórico de Zalamea de La Serena, Badajoz, 1978-1981, PIP IV, Barcelona.

- (1983): El santuario protohistórico de Zalamea de La Serena, Badajoz, II. 1981-1982, PIP V, Barcelona.

Maluquer de Motes, J.; Gracia, F., y Munilla, G. (1990): Alto de la Cruz. Cortes de Navarra. Campañas, 1986-1988, Trabajos de Arqueología 9, Pamplona.

Martinez, C., y Botella, M. C. (1980): El Peñón de la Reina (Alboloduy, Almeria). EAE 112, Madrid.

MARTINEZ NAVARRETE, M. I., y MÉNDEZ, A. (1983): "Arenero de Soto. Yacimiento de fondos de cabaña del horizonte Cogotas I". Estudios de Prehistoria y Arqueologia Madrileñas 2, pp. 183-284.

MERHAV, R. (ed) (1991): Urartu, a Metalworking Center in the First Millenium B.C.E., Jerusalén.

MILlAN, C., y CHICA, G. de la (1958): "Dos bronces hispano-romanos de la Bética", $R A B M$ LXV, pp. 59-65. 
MOLINA, F. (1978): "Definición y sistematización del Bronce Tardio y Final en el Sudeste de la Peninsula Ibérica", Cuadernos de Prehistoria de la Universidad de Granada 3, pp. 175-214.

MORENO, F. J. (1995): "La estela de Arroyo Manzanas (Las Herencias II. Toledo)", Gerión 13. pp. $275-294$.

MUÑNOZ, K. (1993): "El poblamiento desde el Calcolítico a la Primera Edad del Hierro en el valle medio del rio Tajo", Complutum 4, pp. 321-336.

- (1998): El poblamiento desde el Neolitico Final a la Primera Edad del Hierro en la cuenca media del rio Tajo. (Tesis Doctoral inédita). Madrid. Universidad Complutense.

- (1999a). "La Prehistoria Reciente en el Tajo Central (Cal. V-I Milenio a. C.)", Complutum 10. pp. 91-122.

- (1999b): "Mirando al Suroeste de la Celtiberia: nuevos datos sobre la Primera Edad del Hierro en la cuenca media del Tajo", en J. A. Arenas y M. V. Tamayo (coords.) El origen del mundo celtibérico. Actas de los Encuentros sobre el origen del Mundo Celtiberico, Guadalajara, pp. 221-237.

- (e. p.): "Hallazgos neolíticos de las vegas de Aranjuez (Madrid). Nuevos datos sobre el Neolítico del Interior peninsular", Estudios de Prehistoria y Arqueología Madrileña 12.

MuÑoz, K., y MADRIGAL, A. (1999): "Poblamiento y recursos durante la Segunda Edad del Hierro en el valle medio del río Tajo". en F. Burillo (coord.) IV Congreso sobre Celtíberos. Economias, Zaragoza, pp. 467-480.

MUÑOZ, K., y ORTEGA, J. (1997): "Elementos de inspiración orientalizante en la cuenca media del rio Tajo: el yacimiento de "Puente Largo de Jaramas (Aranjuez, Madrid)", Spal6. pp. 141-167.

PELLICER, M. (1988-1989). "La cerámica a mano del Bronce Reciente y del orientalizante en Andalucía Occidental", Habis 17-18, pp. 461-481

Pereira, J., y Álvaro, E. de (1990): "Ei enterramiento de La Casa del Carpio, Belvís de la Jara (Toledo)". Actas del Primer Congreso de Arqueologia de la provincia de Toledo, Toledo pp. 215-234.

PIGGotT, S. (1983) The Earliest Wheeled Transport from the Atlantic Coast to the Caspian Sea, Londres.

QueSADA, F. (1997a): "La Península Iberica", Carri da guerra e principi etruschi, Roma. pp. 53-59.

- (1997b): "Armas para los muertos", Los Iberos Príncipes de Occidente, Barcelona, pp. 125-131.

Rios, J. A. de los (1909): "Cabezas de bronce encontradas en el sitio llamado Máquiz, término de Mengibar", BRAH1, pp. 27-32.

Ruiz MATA, D. (1995): "Las cerámicas del Bronce Final. Un soporte tipológico para delimitar el tiempo y el espacio tartésico". Tartessos: 25 años después 1968-1993. Actas 
del Congreso Conmemorativo del V Simposium Internacional de Prehistoria Peninsular, Jerez de la Frontera, pp. 265-213.

Ruiz Rodriguez, A., y Molinos, M. (1993)' Los Iberos. Análisis arqueológico de un proceso histórico. Barcelona.

Ruiz Zapatero, G. (1985): Los Campos de Urnas del N.E. de la Península lbérica, Colección Tesis Doctorales 83/85, Madrid, Universidad Complutense.

RUANO, E. (1992): El mueble ibérico, Madrid.

ScHÜLE, W. (1969): Die Meseta-Kulturen der Iberischen Halbinsel, MF 3, Berlín.

WoYTowITSCH. E. (1978): Die Wagen der Bronze frühen Eisenzeit in Italien, PBF XVII,1, Munich.

\section{POST-SCRIPTUM}

Estando en prensa este artículo, hemos tenido constancia de la aparición de dos nuevos pasamiendas de bronce expuestos en la vitrina de nuevas adquisiciones del Museu Nacional de Arqueologia e Etnologia de Lisboa (Portugal). Se trata de dos ejemplares de vástago; el primero de cresteria simple calada y el segundo de crestería compleja compuesta por una sucesión de capullos abiertos y cerrados mucho más esquemática que la del ejemplar de la Colección Vives. Se hallaron con un conjunto de atalajes ecuestres formado por un bocado de bronce con camas representando la figura de un Despotes Theron (como los de Cancho Roano, Maluquer, 1983, fig. 12) y filete trenzado con púas de castigo; varios botones cónicos de distintos tipos y tamaños; un asador de tipo andaluz, y el extremo de un cazo o recipiente acabado en cabeza de ánade. El conjunto se situaria en el siglo $v a$. $C$., aunque los pasarriendas deben ser pervivencias más antiguas, idea a la qu conduc, además de su morfología, su disimetria. Este conjunto, en el que no se han localizado más elementos de carro, reforzaria la hipótesis de enterramientos de yugos (pars pro toto) en la Protohistoria peninsular que hemos defendido en este trabajo. 